\title{
1 A spatial model of the plant circadian clock reveals 2 design principles for coordinated timing under noisy 3 environments
}

4 Short title: Coordinated timing through clock coupling

5 Mark Greenwood ${ }^{1,2}$, Isao T. Tokuda ${ }^{3^{*}}$, James C.W. Locke ${ }^{1,4^{*}}$

6 'Sainsbury Laboratory, University of Cambridge, Cambridge, UK

$7 \quad{ }^{2}$ Department of Biochemistry, University of Cambridge, Cambridge, UK

8 '3epartment of Mechanical Engineering, Ritsumeikan University, Kusatsu, Japan

$9 \quad{ }^{4}$ Microsoft Research, Cambridge, UK

10 *For correspondence: james.locke@slcu.cam.ac.uk or isao@fc.ritsumei.ac.jp

12 Abstract

13 Individual plant cells possess a genetic network, the circadian clock, that times internal

14 processes to the day-night cycle. Mathematical models of the clock network have driven a 15 mechanistic understanding of the clock in plants. However, these models are typically either

16 'whole plant' models that ignore tissue or cell type specific clock behavior, or 'phase only'

17 models that do not include clock network components explicitly. It is increasingly clear that in

18 order to reveal the design principles of the plant circadian clock, clock network models must

19 address spatial differences. This is because complex spatial behaviours have been observed in

20 tissues and cells in plants, including period and phase differences between cells and spatial

21 waves of gene expression between organs. Here, we implement an up to date clock network

22 model on a spatial template of the plant. In our model, the sensitivity to light inputs varies across

23 the plant, and cells communicate their clock timing locally via the levels of core clock mRNA

24 levels by cell-to-cell coupling. We found that differences in sensitivities to environmental input in

25 the model can explain the experimentally observed differences in clock periods in different 
organs, and we show using the model that a plausible coupling mechanism can generate the experimentally observed waves in clock gene expression across the plant. We then examined what features of the plant circadian system allow it to keep time under noisy light-dark (LD) cycles. We found that differences in sensitivity to light can allow regional flexibility in phase even under LD cycles, whilst local cell-to-cell coupling minimized variability in clock rhythms in neighboring cells. Thus, local sensitivity to environmental inputs combined with cell-to-cell coupling allows for flexible yet robust circadian timing under noisy environments.

Abbreviations: CCA1, CIRCADIAN CLOCK ASSOCIATED 1; CV, coefficient of variation; DD, constant dark; ELF4, EARLY FLOWERING 4; LD, light-dark; LHY, LATE ELONGATED

HYPOCOTYL; LL, constant light; LUC, LUCIFERASE; LUX, LUX ARRHYTHMO; PRR, PSEUDO-RESPONSE REGULATOR; TOC1, TIMING OF CAB EXPRESSION 1; YFP, yellow fluorescent protein.

\section{Introduction}

41 The circadian clock is a $24 \mathrm{~h}$ genetic oscillator found in many organisms. The clock consists of a

42 circuit of interlocking feedback loops of mRNAs and proteins that generate daily oscillations in

43 circuit component levels. Signals from the environment align the timing of these oscillations to

44 the day-night cycle [1]. Once set, circadian clocks act as an internal timing signal, allowing

45 biological processes to anticipate the external environmental cycles. The clock modulates a

46 diverse range of processes in plants, including cell division, tissue growth, flowering time, and

47 scent emission [2-5]. Altogether this daily timing provides a significant fitness advantage to the 48 plant $[6,7]$.

50 Individual plant cells possess a robust circadian clock [8]. However, substantial differences in 51 the period and phase of clock rhythms across the plant have been observed. Time lapse 
52 imaging experiments with luciferase and fluorescent reporter genes have shown that rhythms in

53 core clock genes oscillate with different speeds in different organs under constant light (LL) [8-

54 13]. Further, experiments under a range of conditions have shown that differences in clock

55 speed and phase can be caused by organs having different sensitivity to environmental signals

56 [12-15]. Differences in the clock network between tissues may also contribute to generating

57 differences in rhythms across the plant, as although the clock genes are broadly expressed [13],

58 some are tissue enriched [16], and mutations can affect organs differently $[11,15,17]$.

60 The observed differences in clock rhythms across the plant raises the question of how clocks in

61 different cells and tissues remain coordinated with each other. One mechanism would be for

62 cells to communicate their timing with their neighbors. High resolution experiments have

63 measured or inferred local coupling of clock rhythms between cells $[8,11,14,16,18-20]$, and

64 local coupling can drive spatial waves of clock gene expression across the plant $[8,14,18-20]$.

65 Longer-distance coupling between clocks is also possible. For example, molecular signals communicate circadian temperature information from the shoot to the root [11,21], and light

67 information may be piped down the stem to entrain the root [22].

Mathematical modeling has played a crucial role in gaining a mechanistic understanding of plant

70 circadian clocks. Models of the network have increased in complexity over time in parallel with

71 the growing number of experiments [23-28]. Recently, these detailed molecular models have

72 been used to probe the differences between the shoot and root clock [13]. However, the

73 coupling of clocks between cells was not considered. For this, more computationally tractable

74 models of the clock network are necessary. Reduced models of the network have already been

75 constructed that capture many of the features of the single cell clock dynamics [29-32].

76 However, these models have not been applied to study spatial dynamics. Instead, 'phase only'

77 models that lack any genetic network information and only consider the phases of individual 
cellular rhythms have been preferred [8,18-20]. Although these models allow the simulation of general oscillatory behavior, owing to their simplicity they are unsuitable for investigating molecular mechanisms of the clock.

Recently, a 'phase only' Kuramoto model [33] was used to propose a mechanism for whole-

83 plant coordination of clocks $[8,14]$. In order to match experimentally measured rhythms, the

84 model fixed clock periods to different speeds in each region of the plant. It assumed faster

85 rhythms in the cotyledons, hypocotyl, and root tip, and slower rhythms in the rest of the root, as observed experimentally. With these periods fixed, cells were allowed to communicate clock

87 phase through local cell-to-cell coupling. With these assumptions, simulations of the model generated waves of clock gene expression within and between organs, as observed experimentally $[8,14]$. Thus, local cell-to-cell coupling could enable coordination between organs in plants.

Multiple questions remain about how the plant clock coordinates rhythms that cannot be

93 addressed using a 'phase only' model. For example, how are the periods set differently in

94 different parts of the plant? What molecular mechanisms allow the coupling of clock rhythms

95 from cell-to-cell? How can the plant clock network 'filter' both internal and environmental noise

96 to robustly entrain to the environment? To begin to address these questions, in this work we

97 developed a spatial network model of the plant circadian system. We modified a previously

98 generated simplified network model and implemented it on a multicellular template of a plant. In

99 our model, the sensitivity to light varies across the plant, and cells communicate via the mRNA

100 levels of a core clock gene. Simulations capture the organ specific period differences and

101 spatial waves observed under LL, demonstrating a plausible mechanism of circadian

102 coordination. We then applied our model to examine how the system keeps time under noisy

103 light-dark (LD) cycles. We found that regional differences persist even under LD cycles, but cell- 
104 to-cell minimized differences between neighbor cells. Thus, the combination of local sensitivity

105 to inputs and cell-to-cell coupling allows for coordinated timing in noisy environments.

\section{Results}

\section{A locally coupled spatial model of the plant circadian clock network}

109 We first implemented a reduced network model of the Arabidopsis thaliana circadian clock [31].

110 To decrease the complexity of the model, the authors grouped functionally similar genes into

111 single entities (Fig 1A). The compact network model incorporates known light inputs to the

112 network and qualitatively recapitulates clock dynamics under both light dark cycles and constant

113 light. At only 9 equations and 34 parameters the model is also computationally tractable for

114 spatial simulations. We modified the De Caluwe model to include a repression rather than

115 activation interaction between PSEUDO-RESPONSE REGULATOR 9 (PRR9)/PRR7 and

CIRCADIAN CLOCK ASSOCIATED 1 (CCA1) / LATE ELONGATED HYPOCOTYL (LHY), as

117 this has recently been shown experimentally [34] (Methods).

We implemented the modified De Caluwe model on a simplified template of a seedling. The template consisted of approximately 800 cells, classified into cotyledon, hypocotyl, root, and

121 root tip regions (Fig 1B and Methods). Although a number of studies have demonstrated local

122 cell-to-cell coupling between clocks in $A$. thaliana $[8,11,14,16,18-20]$, the identity of the coupling 123 components are unclear. Initially, to model the coupling (Fig 1C), the level of CCA1/LHY in one 124 cell was assumed to be locally coupled to the level of the cell's neighbors. The coupling strength 125 was set to 2 (Methods). To simulate the variability observed in single cell clock rhythms [8] we 126 multiplied the level of each mRNA and protein by a time scaling parameter that was randomly

127 selected from a normal distribution (Methods). The range of this normal distribution was set 128 differently for each organ to qualitatively match the variability observed experimentally (S1 Fig). 


\section{Different light sensitivities can explain organ differences in phase and period}

131 We next attempted to recapitulate in our model the differences in clock period and phase in

132 different organs that have been observed in experiments using a single cell CCA1-YFP reporter

133 [8] and a GIGANTEA luciferase reporter [14]. In these experiments, faster rhythms were

134 observed in the cotyledon, hypocotyl, and root tip, with slower rhythms in the rest of the root.

135 We first reanalyzed existing luciferase data [14] and confirmed that these relationships held for

136 several of the core clock genes in our model, PSEUDO-RESPONSE REGULATOR 9 (PRR9),

137 TIMING OF CAB EXPRESSION 1 (TOC1), and EARLY FLOWERING 4 (ELF4) (Fig 2A).

138 Whereas in our previous 'phase only' model, we fixed the periods to be different in each part of

139 the plant, with our spatial network model, we could now investigate what causes the differences

140 in periods. Previously it has been hypothesized that different sensitivities to environmental

141 inputs alter periods across the plant $[13,14]$. For example, cells in the cotyledon may be fast

142 because they are more sensitive to light. Experimental tests of this, however, are confounded by

143 changes in metabolism and development caused by light [35]. To test this in our model, we

144 simulated differences in sensitivity by setting the intensity of light input in our model to differ

145 depending on the region, and examined whether this can generate the period differences

146 observed across the plant.

148 We entrained the cells in our simulations to LD cycles for 4 days before releasing them into LL

149 for a further 6 days and measured the periods, as carried out in previous experiments [14].

150 When assuming high sensitivity to light in the cotyledon $(L=1.35)$ and hypocotyl $(L=1.10)$, but

151 lower in the root $(L=0.90)$ and root tip $(L=1.03)$, all organs entrained to the LD cycles (S2 Fig).

152 Upon transfer to LL, we were able to generate different periods (Fig 2B) and phases (Fig 2D-F

153 and S3 Fig) in each organ, matching those observed experimentally. Thus, our results revealed

154 that different sensitivities to environmental inputs are sufficient to generate the experimentally

155 observed spatial differences in period and phase across the plant. This is due to higher light 
sensitivity causing the clock to run faster in our simulations (S4 Fig), as expected for a diurnal organism [36].

\section{Local sharing of clock mRNA levels can drive spatial waves of clock gene expression}

160 Previously we observed two waves of clock gene expression, one traveling up, and one down 161 the root, in CCA1, PRR9 and $G /$ reporters [8,14]. These waves could be explained in a phase 162 only model by local cell-to-cell coupling $[8,14,19,20]$. We next tested whether a plausible 163 mechanism for cell-to-cell coupling, sharing of mRNA between cells [37], can recapitulate the experimental observations. To provide a benchmark, we first analyzed the seedlings carrying transcriptional reporters for TOC1, PRR9, and ELF4 [14] at the sub-tissue level (Methods). As in previous studies $[8,14,18-20]$, space-time plots revealed spatial waves of gene expression within and between organs (Fig 3A and S5 Fig). The direction of the waves can be clearly observed in plots of the final peaks of expression (Fig 3B and S5 Fig). For each gene, the wave patterns appeared similar, with two waves of clock gene expression in the root (Fig 3C, S5 Fig, and S1 Video).

172 We next analyzed simulations at the sub-tissue level (S6 Fig and Methods) to see if our model 173 captures these spatial dynamics. For each gene, the wave patterns appeared similar to 174 experiments, traveling from the fast oscillating regions that are more sensitive to light, into the 175 slower regions with lower sensitivity to light (Fig 3C, D, S5 Fig and S2 Video). These waves 176 required cell-to-cell coupling through the local sharing of clock mRNA, as we only observed 177 waves with coupling strengths, J, above approximately 1 (Fig 3E and S7 Fig). Similar simulation

178 results were obtained using different clock genes as the coupling component, suggesting that 179 any cell-to-cell sharing of clock components can explain the experimentally observed spatial 180 dynamics (S8 Fig). We also found that our simulation results were qualitatively similar when 181 keeping regional differences of light sensitivity and local cell-to-cell coupling, but assuming no 
182 cell-to-cell variability within regions (S9 Fig). Additionally, we ran simulations assuming longer

183 distance and global coupling. Increasing the local coupling to be between 8 rather than 4

184 neighbor cells gave qualitatively similar results. However, with global coupling all cells adopted

185 the same phase at higher coupling strengths, regardless of position in the plant (S10 Fig).

186 Finally, by setting the light inputs in our locally coupled model to be equal in all regions of the

187 seedling, we were also able to simulate the loss of waves observed in the light sensing mutant

188 phyb-9 [14] (S11 Fig). Taken together, these results show that the assumptions of local cell-to-

189 cell coupling and differential light sensitivity between regions are the key aspects of our model

190 that allow a match to experimental data.

\section{Local flexibility persists under idealized and noisy LD cycles}

193 Our modeling suggests that different sensitivities to environmental inputs across the plant allows

194 the clock to be locally flexible under LL, by allowing it to adopt different periods and phases

across the plant even under the same environment. We simulated our model under LD cycles to

investigate whether local flexibility persisted with rhythmic input. We first simulated idealized LD

cycles, where lights are switched fully on during the daytime and off at night (Fig 4A and

Methods). The sensitivity to light during the daytime differed depending on the region, as with LL simulations, and we first assumed no cell-to-cell coupling $(J=0)$. In the absence of cell-to-cell coupling, close inspection of the final peaks of expression revealed small differences in the

201 timing between regions. PRR5/TOC1 expression in cells of the cotyledon peaked at $132.70 \pm$

$2020.50 \mathrm{~h}$ (median \pm interquartile range), followed by those in the hypocotyl $(133.40 \pm 0.40 \mathrm{~h}$ ) and

203 then the root, with cells at the tip $(133.50 \pm 1.35 \mathrm{~h})$ peaking before those in the middle region of

204 the root (134.80 \pm 1.20 h; Fig 4B, left and S12 Fig). These phase differences were qualitatively

205 the same as observed under LL (Fig 2 and 3) but were discontinuous between regions. With the

206 addition of cell-to-cell coupling, the phase differences between regions were no longer

207 discontinuous and were instead staggered, causing the emergence of spatial waves (Fig 4B, 
middle and right, and S12 Fig). However, phase differences between the regions persisted and did not reduce in size with increasing strengths of coupling (S12 Fig). For example, there was a difference between the cotyledon and root of $1.90 \pm 0.18 \mathrm{~h}$ (median \pm interquartile range)

211 without coupling $(J=0), 2.00 \pm 0.20 \mathrm{~h}$ with coupling $(J=2)$, and $2.00 \pm 0.18 \mathrm{~h}$ with stronger

212 coupling $(J=4)$. A similar spatial structure was observed in CCA1/LHY and PRR9/PRR7

213 expression (S12 Fig). However, ELF4/LUX appeared more synchronized when the peak

214 coincided with the dark transition, as darkness causes strong repression of ELF4 expression.

216 We next simulated more realistic LD cycles containing fluctuations in the light intensity (Fig 4C).

217 These LD cycles were designed to approximate the differences in input that cells may

218 experience due to weather or a cell's microenvironment (Methods). Examination of the times of

219 the final peaks of expression reveals large variation in peak times within regions when cell-to-

220 cell coupling was absent $(J=0 ;$ Fig 4D, left). This made any difference in phase between

221 regions difficult to resolve. However, with increasing strengths of cell-to-cell coupling we

222 observed a decrease in variability. For example, there was a difference of $5.00 \pm 1.05 \mathrm{~h}$ (median

$223 \pm$ interquartile range) between the earliest and latest peaking cells without coupling $(J=0)$, but

$2243.10 \pm 0.23 \mathrm{~h}$ with coupling $(J=2)$, and $3.20 \pm 0.15 \mathrm{~h}$ with stronger coupling $(J=4)$. This

225 decrease in cell-to-cell variation revealed an underlying spatial structure (Fig 4D, middle and 226 right, and S13 Fig), comparable to that observed under idealized LD cycles (Fig 4B, middle and 227 right, and S12 Fig). Phase differences and spatial waves persisted with increasing strengths of 228 coupling (S13 Fig). This spatial structure was also observed in expression of CCA1/LHY and $229 P R R 9 / P R R 7$, but not in ELF4/LUX expression (S13 Fig). Together this shows that local flexibility

230 in phase, and spatial waves, persisted under LD cycles when local cell-to-cell coupling was

231 present. 
234 Simulations under noisy LD cycles showed that whilst local flexibility of regions persisted, cell-

235 to-cell coupling decreased the phase variation within regions (Fig 4). We further investigated the

236 function of cell-to-cell coupling by testing whether coupling also affected the global

237 synchronization of rhythms, or is limited to a local effect on rhythms. To test this, we quantified

238 the synchrony between all cells within the template seedling using a score for synchronization,

$239 R$ [38]. The synchronization index, $R$, is the ratio of the variance of the average signal to the

240 average variance of the individual cells. When cells are synchronized these variances are equal

241 to each other and $R$ becomes 1 , whereas when desynchronized $R$ becomes 0 . For each gene

242 pair, we observed a high $R$ value under idealized LD cycles, with or without cell-to-cell coupling

243 (Fig 5, black lines). However, cells were less synchronous under noisy LD cycles (Fig 5, red

244 lines). Each gene showed a reduced level of synchrony in the absence of cell-to-cell coupling ( $J$

$245=0) . P R R 9 / P R R 7$ was the most affected by the noise, with a synchronization index of $0.97 \pm$

2460.002 (mean \pm standard deviation) under idealized LD and $0.61 \pm 0.008$ under noisy LD cycles

247 (Fig 5B). This is likely because $P R R 9 / P R R 7$ synthesis is most strongly affected by light (Table

248 1).

250 We observed an increase in global synchronization under noisy LD cycles as coupling strengths

251 increased (Fig 5). At higher strengths of coupling $(J>2)$, for CCA1/LHY and PRR5/TOC1 the

252 synchronization index under noisy LD cycles approximately equaled that under idealized LD

253 cycles (Fig 5A and C). For PRR9/PRR7 and ELF4/LUX expression, the synchronization index

254 increased with increasing strength of coupling, but did not reach the level observed under

255 idealized LD cycles for all strengths tested (Fig 5B and D). Oscillations of protein expression

256 also increased in synchrony with cell-to-cell coupling (S14 Fig). Thus, local cell-to-cell coupling

257 improves the global coordination of circadian timing under noisy light-dark cycles, whilst still

258 allowing differences in clock timing between regions. 


\section{Discussion}

261 Here we develop a spatial network model for the plant clock and use it to examine the design

262 principles of clock coordination in plants. This simple multicellular model, which assumes

263 regional differences in sensitivity to light and cell-to-cell coupling through the local sharing of

264 clock mRNA levels, successfully simulates the period differences and phase waves across the

265 plant observed under LL in previous time lapse experiments. Our simulations predict that phase

266 flexibility persists under LD cycles, with cell-to-cell coupling reducing cell-to-cell differences but

267 still allowing regional flexibility. We therefore find that the plant circadian clock system can

268 combine regional differences in environmental signaling with cell-to-cell coupling to enable

269 robust, yet flexible, circadian timing under noisy environmental cycles.

270

271 Previous models of the plant circadian clock have proven important for understanding aspects

272 of plant physiology, including starch metabolism and flowering [39,40]. However, it was recently

273 shown that the clock controls physiology in a tissue-specific manner. For example, clocks in the

274 epidermis regulate growth, whereas those in the vasculature regulate flowering [41]. In future,

275 our spatial model could be extended to investigate circadian control of physiology at the cell and

276 tissue level. An interesting example will be cell division, which is regulated by the clock [2], and

277 occurs in meristematic regions of the plant [42]. It will be interesting to see if, and how, flexibility

278 of the circadian system impacts tightly controlled phenotypes such as this.

280 Including noise in LD cycles represents a step towards understanding how the plant circadian

281 system works under natural conditions. Our simulations under noisy LD cycles reveal that local

282 cell-to-cell coupling allows a balance between ensuring cells are coordinated locally even under

283 a noisy environment, whilst still allowing regional differences that would not be possible with a

284 global coupling mechanism. However, this is still a simplification of the real environment. For

285 example, we do not consider temperature, which is phase shifted between the air and soil [43]. 
Although technically challenging, experiments under more realistic conditions such as this will be important for furthering our understanding. Promising advances in this direction include the GLO-Roots system [44], and the robotics of Bordage et al. [13], which allow the root to be imaged in the dark under LD cycles. As experiments progress, we predict that spatial models such as ours will be crucial for understanding how the clock integrates such a range of

291 environmental signals across the plant.

293 The molecular details underlying the spatial differences, and coordination, of the plant circadian 294 system are still being deciphered. Recently, ELF3, ELF4, and LUX were found to be central to 295 the difference between the shoot and root, possibly due to their interaction with the light signaling protein PHYB [15]. However, interpretation is hindered by the fact that components causing differences could also act as a cell-to-cell mobile coupling signal. For example, ELF4 has also been proposed to move from the shoot to couple with clocks in the root [21]. We note that our spatial molecular model has the potential to delineate these two effects. In future work it will be important to vary the identity of the coupling signal, and the underlying genetic network,

301 to generate testable predictions.

The plant circadian system, with local inputs to cells that are coupled together, represents a

304 decentralized structure. This is in contrast to the centralized mammalian circadian system [45].

305 Here we found that this decentralized structure can afford plants flexibility, allowing regions to

306 adopt different phases under noisy LD cycles. It could be speculated that this has a

307 physiological effect on plants, causing, for example, a stagger in the timing of growth across the

308 plant. However, further work is required to understand how, or whether, this flexibility is an

309 advantage to plants.

\section{Acknowledgments}


MG and JL were supported by the Gatsby Charitable Foundation (grant number GAT3395/GLC) and IT by the Japan Society for the Promotion of Science (grant numbers 17H06313,

314 18H02477, and 20K11875). We thank Dr. Katie Abley (University of Cambridge) for critical

315 reading of the manuscript.

\section{Conflicts of Interests}

318 The authors declare that they have no conflict of interest.

\section{Methods}

\section{$321 \quad$ Single cell molecular model}

322 As a model for the plant circadian clock, we exploit the compact model introduced by De

323 Caluwe et al. [31]. The original compact model consists of 9 ordinary differential equations.

324 Among them, 8 equations describe the temporal evolution of the mRNA and protein levels of the 325 core clock genes. The clock genes are grouped into four sets of lumped pairs labeled as: CL 326 (CCA1 and LHY), P97 (PRR9 and PRR7), P51 (PRR5 and TOC1) and EL (ELF4 and LUX). The 327 9-th equation is for the light-sensitive protein P (PIF3 and PIL1).

329 In our modeling, one modification to the original compact model was made. According to the 330 experiments reported in [46], the compact model assumed that the P97 variable is activated by 331 CL. However, more recent work [28,34], has shown that $L H Y$ acts as a repressor of all other 332 clock components, including $P R R 9$ and $P R R 7$. We therefore replaced the activation term that 333 represents the connection from CL to P97 with a repression. The revised single cell model is 334 now described by the following differential equations:

$335 \frac{d c_{C L}^{(m)}}{d t}=\left(v_{1}+v_{1 L} L(t) c_{P}^{(p)}\right) \frac{1}{1+\left(c_{C L}^{(p)} / K_{0}\right)^{2}+\left(c_{P 97}^{(p)} / K_{1}\right)^{2}+\left(c_{P 51}^{(p)} / K_{2}\right)^{2}}-\left(k_{1 L} L(t)+k_{1 D} D(t)\right) c_{C L}^{(m)}$, 
$\frac{d c_{C L}^{(p)}}{d t}=\left(p_{1}+p_{1 L} L(t)\right) c_{C L}^{(m)}-d_{1} c_{C L}^{(p)}$

337

$\frac{d c_{P 97}^{(m)}}{d t}=\left(v_{2 L} L(t) c_{P}^{(p)}+v_{2 A}\right) \frac{1}{1+\left(c_{P 51}^{(p)} / K_{4}\right)^{2}+\left(c_{E L}^{(p)} / K_{5}\right)^{2}+\left(c_{C L}^{(p)} / K_{5 b}\right)^{2}}-k_{2} c_{P 97}^{(m)}$,

338

$\frac{d c_{P 97}^{(p)}}{d t}=p_{2} c_{P 97}^{(m)}-\left(d_{2 D} D(t)+d_{2 L} L(t)\right) c_{P 97}^{(p)}$

339

$\frac{d c_{P 51}^{(m)}}{d t}=v_{3} \frac{1}{1+\left(c_{C L}^{(p)} / K_{6}\right)^{2}+\left(c_{P 51}^{(p)} / K_{7}\right)^{2}}-k_{3} c_{P 51}^{(m)}$,

340

$\frac{d c_{P 51}^{(p)}}{d t}=p_{3} c_{P 51}^{(m)}-\left(d_{3 D} D(t)+d_{3 L} L(t)\right) c_{P 51}^{(p)}$,

341

$\frac{d c_{E L}^{(m)}}{d t}=L(t) v_{4} \frac{1}{1+\left(c_{C L}^{(p)} / K_{8}\right)^{2}+\left(c_{P 51}^{(p)} / K_{9}\right)^{2}+\left(c_{E L}^{(p)} / K_{10}\right)^{2}}-k_{4} c_{E L}^{(m)}$,

342

$\frac{d c_{E L}^{(p)}}{d t}=p_{4} c_{E L}^{(m)}-\left(d_{4 D} D(t)+d_{4 L} L(t)\right) c_{E L}^{(p)}$,

343

$\frac{d c_{P}^{(p)}}{d t}=0.3\left(1+c_{P}^{(p)}\right) D(t)-c_{P}^{(p)} L(t)$.

$344 c_{\alpha}^{(m)}$ and $c_{\alpha}^{(p)}$ represent the concentration of the $\alpha$-th mRNA and protein (or protein complex)

345 respectively, for $\alpha=\mathrm{CL}, \mathrm{P} 97, \mathrm{P} 51, \mathrm{EL}$, and $\mathrm{P} . \mathrm{L}(\mathrm{t})$ represents the input light signal $(L=0$, lights

346 off; $L>0$, lights on) and $D(t)$ denotes a corresponding darkness input signal $(D=1$, lights off; $D$

$347=0$, lights on). The model contains 34 parameters, the values of which have been obtained

348 previously through automated optimization [31]. The parameter values for $K_{0}, K_{4}, K_{5}, K_{5 b}$ related

349 to the modified interaction from CL to P97 were optimized by minimizing the cost function

350 detailed in the following subsection. Sobol search and simulated annealing were combined to

351 optimize within the range $K_{i} \in[0.1,10]$ for $i=0,4,5,5 b$. The optimized parameter values together

352 with the original values determined by De Caluwe et al. [31] are listed in S1 Table. The free

353 running periods of the revised model are $25.5 \mathrm{~h}(\mathrm{LL} ; \mathrm{L}=1)$ and $26.25 \mathrm{~h}(\mathrm{DD} ; \mathrm{D}=1)$. Under LD

354 cycles, peak times $(\mathrm{ZT})$ of the gene expressions were $\mathrm{CL}=0.50 \mathrm{~h}, \mathrm{P} 97=8.25 \mathrm{~h}, \mathrm{P} 51=17.50 \mathrm{~h}$,

355 and $E L=11.75 \mathrm{~h}$. 


\section{Cost function}

358 In the parameter optimization of the single cell model, the cost function was computed as

359 follows. First, the model was simulated under 12-h light-12-h dark conditions for a total of 60 360 days and then released into LL for 60 days, followed by constant dark (DD) for 60 days. In each 361 light condition, the first 55 days were discarded as a transient dynamic. To ensure detectable 362 rhythmicity under LL and DD conditions, all variables were required to have a minimum 363 value of 0.1 , as well as a minimum difference of $10 \%$ between their minimum and maximum 364 values. Any solution that did not meet these criteria was penalized with an arbitrarily large 365 score. Then, the free-running period was calculated using the chi-square periodogram [47] from $366 \mathrm{CL}$ gene expression, at a significance level of $1 \%$. A score of 0 was given to a solution having a 367 free-running period between 24 and $25 \mathrm{~h}$ under LL and between 25 and $28 \mathrm{~h}$ under DD.

368 Solutions with free-running periods outside these ranges were allocated the scores of $\left(\tau_{L L}-\right.$ $36924.5)^{2} /(0.1 \cdot 24.5)^{2}$ and $\left(\tau_{D D}-26.5\right)^{2} /(0.1 \cdot 26.5)^{2}$, where $\tau_{L L}$ and $\tau_{D D}$ represent free-running 370 periods under LL and DD, respectively. For simulations under 12-h light-12-h dark cycles, 371 solutions that were not entrained to the LD cycles were penalized with an arbitrarily large score.

372 Entrained solutions were given a score of 0 for each gene that attained peak expression within \pm $3731 \mathrm{~h}$ of the expected ZT, which were as follows: $\mathrm{CL}=1.5, \mathrm{P} 97=6, \mathrm{P} 51=12$, and $\mathrm{EL}=9$.

374 Expression peaks lying outside these intervals were scored as $\left(Z T_{C L}-1.5\right)^{2} /(0.1 \cdot 24)^{2}$,

$375\left(Z T_{P 97}-6\right)^{2} /(0.1 \cdot 24)^{2},\left(Z T_{P 51}-12\right)^{2} /(0.1 \cdot 24)^{2},\left(Z T_{E L}-9\right)^{2} /(0.1 \cdot 24)^{2}$, where $Z T_{\alpha}$ denotes

376 Zeitgeber time of the $\alpha$-th gene's peak expression.

\section{Spatial molecular model}

379 To simulate the spatial dynamics, we implemented the revised model on a simplified template of 380 a plant. The template consisted of approximately 800 cells, classified into cotyledon, hypocotyl, 
381 root, and root tip regions (Fig 1B). Each cell contained an implementation of the revised

382 compact model. To simulate growth of the seedlings, we added a row of cells to the root tip

383 every $24 \mathrm{~h}$. During this growth, the root tip region of the template was kept fixed in size. To do

384 this, after the addition of new cells, the previously uppermost root tip cells became root cells

385 instead.

386

387 As the coupling agents have yet to be clearly identified by experimental studies, the individual

388 cells are assumed to be coupled through CL. Our model for coupled plant cells is described as

389 follows:

390

$\tau_{i} \frac{d c_{C L, i}^{(m)}}{d t}=\left(v_{1}+v_{1 L} L(t) c_{P, i}^{(p)}\right) \frac{1}{1+\left(c_{C L, i}^{(p)} / K_{0}\right)^{2}+\left(c_{P 97, i}^{(p)} / K_{1}\right)^{2}+\left(c_{P 51, i}^{(p)} / K_{2}\right)^{2}}$

391

$$
-\left(k_{1 L} L(t)+k_{1 D} D(t)\right) c_{C L, i}^{(m)}+J\left(\bar{c}_{C L, i}^{(m)}-c_{C L, i}^{(m)}\right)
$$

392

$\tau_{i} \frac{d c_{C L, i}^{(p)}}{d t}=\left(p_{1}+p_{1 L} L(t)\right) c_{C L, i}^{(m)}-d_{1} c_{C L, i}^{(p)}$

$\tau_{i} \frac{d c_{P 97, i}^{(m)}}{d t}=\left(v_{2 L} L(t) c_{P, i}^{(p)}+v_{2 A}\right) \frac{1}{1+\left(c_{P 51, i}^{(p)} / K_{4}\right)^{2}+\left(c_{E L, i}^{(p)} / K_{5}\right)^{2}+\left(c_{C L, i}^{(p)} / K_{5 b}\right)^{2}}-k_{2} c_{P 97, i^{\prime}}^{(m)}$

$394 \quad \tau_{i} \frac{d c_{P 97, i}^{(p)}}{d t}=p_{2} c_{P 97, i}^{(m)}-\left(d_{2 D} D(t)+d_{2 L} L(t)\right) c_{P 97, i}^{(p)}$,

$\tau_{i} \frac{d c_{P 51, i}^{(m)}}{d t}=v_{3} \frac{1}{1+\left(c_{C L, i}^{(p)} / K_{6}\right)^{2}+\left(c_{P 51, i}^{(p)} / K_{7}\right)^{2}}-k_{3} c_{P 51, i}^{(m)}$

$\tau_{i} \frac{d c_{P 51, i}^{(p)}}{d t}=p_{3} c_{P 51, i}^{(m)}-\left(d_{3 D} D(t)+d_{3 L} L(t)\right) c_{P 51, i}^{(p)}$

397

$\tau_{i} \frac{d c_{E L, i}^{(m)}}{d t}=L(t) v_{4} \frac{1}{1+\left(c_{C L, i}^{(p)} / K_{8}\right)^{2}+\left(c_{P 51, i}^{(p)} / K_{9}\right)^{2}+\left(c_{E L, i}^{(p)} / K_{10}\right)^{2}}-k_{4} c_{E L, i}^{(m)}$,

398

$\tau_{i} \frac{d c_{E L, i}^{(p)}}{d t}=p_{4} c_{E L, i}^{(m)}-\left(d_{4 D} D(t)+d_{4 L} L(t)\right) c_{E L, i}^{(p)}$ 
$399 \tau_{i} \frac{d c_{P, i}^{(p)}}{d t}=0.3\left(1+c_{P, i}^{(p)}\right) D(t)-c_{P, i}^{(p)} L(t)$.

400 As in the revised single cell model, $c_{\alpha}^{(m)}$ and $c_{\alpha}^{(p)}$ represent the concentration of the $\alpha$-th mRNA

401 and protein (or protein complex) respectively for $\alpha=\mathrm{CL}, \mathrm{P} 97, \mathrm{P} 51, \mathrm{EL}$, and $\mathrm{P}$, in the $i$-th cell

$402(i=1,2, \ldots, N)$. In the first equation, the CL gene is locally and diffusively coupled to its

403 neighboring cells, where $J$ is the coupling strength and $\bar{c}_{C L, i}^{(m)}=\frac{1}{4} \sum_{j \in N(i)} C_{C L, j}^{(m)}$ represents averaged

404 expression level over 4 neighboring cells (left, right, above, and below). In the case of coupling

405 between 8 neighboring cells (left, right, above, below, left above, left below, right above, and

406 right below), the averaged expression level becomes $\bar{c}_{C L, i}^{(m)}=\frac{1}{8} \sum_{j \in N(i)} c_{C L, j}^{(m)}$, or $\bar{c}_{C L, i}^{(m)}=\frac{1}{N} \sum_{j=1}^{N} c_{C L, j}^{(m)}$

407 for the case of globally coupled cells. The coupling strength was set to $J=0,0.001,0.01,0.1,1,2$,

408 or 4 .

409

410 Differential light input to cells

411 We set the light strength, $L$, to vary depending on the position of the cell. In doing so, we found

412 that modest differences in $L$ were sufficient to generate period differences between regions. To

413 approximate the period differences that we observed between regions in experiments (Fig 2A)

414 we set $L=1.35$ for cotyledon cells, $L=1.10$ for hypocotyl cells, $L=0.90$ for root cells, and $L=$

4151.03 for root tip cells. As the template of the seedling grew, we kept the root tip region of fixed

416 size (see 'Spatial molecular model'). This meant that the uppermost root tip cells become root

417 cells instead. After this transition, the light input decreased so that cells received a level

418 characteristic of root cells, $L=0.90$. This caused these cells to slow.

420 To generate cell-to-cell variability in periods, the time scaling parameters $\tau_{i}$ were set according

421 to normal distributions as $\mathrm{N}(1,0.059), \mathrm{N}(1,0.028), \mathrm{N}(1,0.073), \mathrm{N}(1,0.089)$ for the four regions,

422 as informed by the analysis of single cell data [8]. For these values of $L$ and $\tau_{i}$, the intrinsic 
423 periods of the 4 regions $(J=0)$ in the absence of growth were $23.2 \pm 1.4 \mathrm{~h}, 25.5 \pm 0.7 \mathrm{~h}, 27.9$

$424 \pm 2.0 \mathrm{~h}$, and $26.3 \pm 2.3 \mathrm{~h}$ (mean \pm standard deviation) respectively.

425

426 Characterizing clock periods from experiments

427 We analyzed experimental luciferase and confocal data to characterize the periods within a

428 seedling. We previously completed an organ-level analysis of period and phase for PRR9::LUC,

429 ELF4::LUC, and TOC1::LUC expression [14]. In this analysis, $315 \mu \mathrm{m}$ diameter regions of

430 interest (ROI) were defined to represent the cotyledon, hypocotyl, root, and root tip regions of

431 the seedling. These ROI were used to generate time series, from which period estimates were

432 made across a number of individual seedlings. Here, we pooled estimates made from

433 PRR9::LUC, ELF4::LUC, and TOC1::LUC lines, and calculated the mean for each region (Fig

$4342 \mathrm{~A}$ ). Only periods from time series classified as rhythmic (as defined previously [14]) were used

435 in the calculation.

437 To characterize the variability of the periods, we measured the between-cell variation of clock

438 periods in each region of the plant (S1 Fig). To do this we analyzed a dataset of single cell time-

439 lapse microscopy, CCA1-YFP translational fusion data [8]. We defined cells as being within the

440 root tip region if they are less than $315 \mu \mathrm{m}$ from the most distal cell of the root tip. Where there

441 are multiple imaging sections in the same organ, cells are pooled to give one region for the

442 cotyledon, hypocotyl, and root. Variability was estimated using the coefficient of variation (CV;

443 standard deviation / mean) of all cells within these regions. Only periods from time series

444 classified as rhythmic (as defined previously [8]) were used in the calculation.

\section{Organ-level analysis}

447 To assess our model we quantified the times of the peaks of expression. For experimental data, 448 we used the ROI positions defined previously [14]. For the model, we defined 5-by-3 (width-by- 
449 height) pixel ROI on the seedling template, approximating the positions used in the experimental

450 analysis of (S6 Fig). The mean of these ROI at each time point were taken to give the simulated

451 time series. Peaks within 24-144 h after transfer to LL were identified using the "findpeaks"

452 MATLAB (MathWorks, UK) function, with the constraint that peaks must be more than $19 \mathrm{~h}$

453 apart. For visual clarity, only peaks in which all organs completed the full cycle within the time

454 window were plotted. Peaks of simulated expression were plotted against previously published

455 experimental data for comparison (e.g. Fig 2D-F) [14]. Only peaks from experimental time

456 series classified as rhythmic (as defined previously [14]) were plotted.

\section{Space-time plots}

459 To visualize the spatial clock dynamics, we created space-time plots of gene expression (e.g.

460 Fig 3A). We made plots of PRR9::LUC, ELF4::LUC, and TOC $1:$ LUC expression as described

461 previously [14]. Individual time series of the space-time plots were background subtracted and

462 small gaps caused by segmentation errors were interpolated. A third-order Butterworth filter was

463 then applied to reduce the high frequency noise. To create space-time plots of simulated clock

464 gene expression, we also extracted the expression from sections that are perpendicular to the

465 primary axis of the seedling (S6 Fig). We take the mean expression from 1-by-5 cell cross-

466 sections of the template. To aid interpretation of space-time plots, amplitude trends were

467 removed from both experimental and model space-time plots using part of the mFourFit

468 algorithm [25].

469

470 We additionally plotted the times of the final peaks of expression of the space-time plots (e.g.

471 Fig 3B). The final oscillation in which all organs completed the full cycle was used. We detected

472 peaks within a $24 \mathrm{~h}$ window of the expected time of these peaks. If more than one peak was

473 detected, we plotted the peak with the highest height. 


\section{Entrainment to noisy LD cycles}

476 We modelled entrainment by simulating light cycles with a day length of $12 \mathrm{~h}$. The level of light

477 during the day varied depending on the region of the template, matching $L$ values under LL. We

478 termed these cycles without noise 'idealized LD' (Fig 4A). To simulate fluctuations in the light

479 cycle we utilized an algorithm developed previously [48], which approximates meteorological

480 data [49]. Fluctuations lasted a random interval of time drawn from an exponential distribution of

481 mean $2.4 \mathrm{~h}$. The intensity of light during each fluctuation was drawn from a second uniform

482 distribution of the range 0 to $L_{\max }$, with $L_{\max }$ matching the $L$ values for the cell under $L L$. The

483 values are set according to the position of the cell on the template, as under LL. We termed this

484 condition 'noisy LD' (Fig 4D). We made the simplifying assumption that each cell is exposed to

485 an independent noisy LD cycle due to their unique positions in the environment. LD cycles were

486 input to the molecular model through the parameter $L$.

Synchrony analysis

489 We estimated the global synchrony in simulations from the variance of the individual cells (Fig 5 490 and S14 Fig). Firstly, the average signal of all $N$ cells of the simulation $\left\{x_{h}(t): h=1,2, \ldots, N\right\}$,

491 was computed as $M(t)=\frac{1}{N} \sum_{h=0}^{N} x_{h}(t)$. Then the overall level of synchrony was measured by 492 the synchronization index [38],

$$
R=\frac{\left\langle M^{2}\right\rangle-\langle M\rangle^{2}}{\frac{1}{N} \sum_{h}^{N}\left\{\left\langle x_{h}{ }^{2}\right\rangle-\left\langle x_{h}\right\rangle^{2}\right.},
$$

494 where \langle\rangle denotes the time average, which in our case was between 0 and $144 \mathrm{~h}$. The

495 synchronization index measures the ratio of the variance of the average signal to the average

496 variance of the individual cells. The parameter quantifies the distribution of both the phases and

497 amplitudes of the individual cells. However, we normalized the individual traces to remove 
amplitude variance and therefore measured only the phase differences. $R$ ranges from 1 when

499 cells are synchronized, to 0 when cells are completely desynchronized.

$501 \quad$ References

502 1. Webb AAR, Seki M, Satake A, Caldana C. Continuous dynamic adjustment of the plant

503 circadian oscillator. Nat Commun. 2019;10: 550. doi:10.1038/s41467-019-08398-5

504 2. Fung-Uceda J, Lee K, Seo PJ, Polyn S, De Veylder L, Mas P. The Circadian Clock Sets

505 the Time of DNA Replication Licensing to Regulate Growth in Arabidopsis. Dev Cell.

506 2018;45: 101-113. doi:10.1016/j.devcel.2018.02.022

507 3. Nozue K, Covington MF, Duek PD, Lorrain S, Fankhauser C, Harmer SL, et al. Rhythmic growth explained by coincidence between internal and external cues. Nature. 2007;448: 358-361. doi:10.1038/nature05946

4. Fenske MP, Nguyen LP, Horn EK, Riffell JA, Imaizumi T. Circadian clocks of both plants and pollinators influence flower seeking behavior of the pollinator hawkmoth Manduca sexta. Sci Rep. 2018;8: 2842. doi:10.1038/s41598-018-21251-x

5. Greenwood M, Locke JC. The circadian clock coordinates plant development through specificity at the tissue and cellular level. Curr Opin Plant Biol. 2020;53: 65-72. doi:10.1016/j.pbi.2019.09.004

6. Dodd AN, Salathia N, Hall A, Kevei E, Toth R, Nagy F, et al. Plant Circadian Clocks

519 7. Green RM, Tingay S, Wang Z-Y, Tobin EM. Circadian rhythms confer a higher level of fitness to Arabidopsis plants. Plant Physiol. 2002;129: 576-84. doi:10.1104/pp.004374

8. Gould PD, Domijan M, Greenwood M, Tokuda IT, Rees H, Kozma-Bognar L, et al. 
524 9. Thain SC, Murtas G, Lynn JR, McGrath RB, Millar AJ. The circadian clock that controls gene expression in Arabidopsis is tissue specific. Plant Physiol. 2002;130: 102-110. doi:10.1104/pp.005405

10. Yakir E, Hassidim M, Melamed-Book N, Hilman D, Kron I, Green RM. Cell autonomous and cell-type specific circadian rhythms in Arabidopsis. Plant J. 2011;68: 520-531. doi:10.1111/j.1365-313X.2011.04707.x

11. Takahashi N, Hirata Y, Aihara K, Mas P. A Hierarchical Multi-oscillator Network Orchestrates the Arabidopsis Circadian System. Cell. 2015;163: 148-159.

12. James AB, Monreal JA, Nimmo GA, Kelly CL, Herzyk P, Jenkins GI, et al. The circadian clock in Arabidopsis roots is a simplified slave version of the clock in shoots. Science. 2008;322: 1832-5. doi:10.1126/science.1161403

13. Bordage S, Sullivan S, Laird J, Millar AJ, Nimmo HG. Organ specificity in the plant circadian system is explained by different light inputs to the shoot and root clocks. New Phytol. 2016;212: 136-49. doi:10.1111/nph.14024

14. Greenwood M, Domijan M, Gould PD, Hall AJW, Locke JCW. Coordinated circadian timing through the integration of local inputs in Arabidopsis thaliana. PLoS Biol. 2019;17: e3000407. doi:https://doi.org/10.1371/journal.pbio.3000407

15. Nimmo HG, Laird J, Bindbeutel R, Nusinow DA. The evening complex is central to the

16. Endo M, Shimizu H, Nohales MA, Araki T, Kay SA. Tissue-specific clocks in Arabidopsis difference between the circadian clocks of Arabidopsis thaliana shoots and roots. Physiol Plant. 2020; ppl.13108. doi:10.1111/ppl.13108

547 17. Lee HG, Seo PJ. Dependence and independence of the root clock on the shoot clock in Arabidopsis. Genes Genomics. 2018;40: 1063-1068. doi:10.1007/s13258-018-0710-4

549 18. Wenden B, Toner DLK, Hodge SK, Grima R, Millar AJ. Spontaneous spatiotemporal 
waves of gene expression from biological clocks in the leaf. Proc Natl Acad Sci U S A. 2012;109: 6757-6762. doi:10.1073/pnas.1118814109

19. Fukuda $\mathrm{H}$, Nakamichi N, Hisatsune M, Murase H, Mizuno T. Synchronization of Plant Circadian Oscillators with a Phase Delay Effect of the Vein Network. Phys Rev Lett. 2007;99: 098102. doi:10.1103/PhysRevLett.99.098102

20. Fukuda H, Ukai K, Oyama T. Self-arrangement of cellular circadian rhythms through phase-resetting in plant roots. Phys Rev E. 2012;86: 041917. doi:10.1103/PhysRevE.86.041917

21. Chen WW, Takahashi N, Hirata Y, Ronald J, Porco S, Davis SJ, et al. A mobile ELF4 delivers circadian temperature information from shoots to roots. Nat Plants. 2020;6: 416426. doi:10.1038/s41477-020-0634-2

22. Nimmo HG. Entrainment of Arabidopsis roots to the light:dark cycle by light piping. Plant Cell Environ. 2018;41: 1742-1748. doi:10.1111/pce.13137

23. Locke JCW, Southern MM, Kozma-Bognár L, Hibberd V, Brown PE, Turner MS, et al. analysis. Mol Syst Biol. 2005;1: 2005.0013. doi:10.1038/msb4100018

24. Locke JCW, Kozma-Bognár L, Gould PD, Fehér B, Kevei E, Nagy F, et al. Experimental

25. Edwards KD, Akman OE, Knox K, Lumsden PJ, Thomson AW, Brown PE, et al.

Quantitative analysis of regulatory flexibility under changing environmental conditions.

572 26. Pokhilko A, Hodge SK, Stratford K, Knox K, Edwards KD, Thomson AW, et al. Data assimilation constrains new connections and components in a complex, eukaryotic circadian clock model. Mol Syst Biol. 2010;6: 416. doi:10.1038/msb.2010.69

575 27. Pokhilko A, Fernández AP, Edwards KD, Southern MM, Halliday KJ, Millar AJ. The clock 
gene circuit in Arabidopsis includes a repressilator with additional feedback loops. Mol Syst Biol. 2012;8: 574. doi:10.1038/msb.2012.6

578 28. Fogelmark K, Troein C. Rethinking transcriptional activation in the Arabidopsis circadian clock. PLoS Comput Biol. 2014;10: e1003705. doi:10.1371/journal.pcbi.1003705

29. Akman OE, Watterson S, Parton A, Binns N, Millar AJ, Ghazal P. Digital clocks: simple

Boolean models can quantitatively describe circadian systems. J R Soc Interface. 2012;9: 2365-2382. doi:10.1098/rsif.2012.0080

30. Foo M, Somers DE, Kim P-J. Kernel Architecture of the Genetic Circuitry of the Arabidopsis Circadian System. Jensen LJ, editor. PLoS Comput Biol. 2016;12: e1004748. doi:10.1371/journal.pcbi.1004748

31. De Caluwé J, Xiao Q, Hermans C, Verbruggen N, Leloup J-C, Gonze D. A Compact Model for the Complex Plant Circadian Clock. Front Plant Sci. 2016;7: 74. doi:10.3389/fpls.2016.00074

32. Tokuda IT, Akman OE, Locke JCW. Reducing the complexity of mathematical models for the plant circadian clock by distributed delays. J Theor Biol. 2019;463: 155-166. doi:10.1016/J.JTBI.2018.12.014

33. Kuramoto $\mathrm{Y}$. Self-entrainment of a population of coupled non-linear oscillators. International Symposium on Mathematical Problems in Theoretical Physics. Berlin/Heidelberg: Springer-Verlag; 1975. pp. 420-422. doi:10.1007/bfb0013365

34. Adams S, Manfield I, Stockley P, Carre IA, Dowidar N, Dunaway D. Revised Morning Loops of the Arabidopsis Circadian Clock Based on Analyses of Direct Regulatory Interactions. Foulkes NS, editor. PLoS One. 2015;10: e0143943. doi:10.1371/journal.pone. 0143943

35. Taiz L, Zeiger E, Møller IM, Murphy A. Plant Physiology and Development. 6th ed. Sunderland: Sinauer Associates; 2018.

36. Aschoff $\mathrm{J}$, Pohl $\mathrm{H}$. Phase relations between a circadian rhythm and its zeitgeber within 
603 37. Maizel A, Markmann K, Timmermans M, Wachter A. To move or not to move: roles and specificity of plant RNA mobility. Curr Opin Plant Biol. 2020;57: 52-60. doi:10.1016/j.pbi.2020.05.005

38. Garcia-Ojalvo J, Elowitz MB, Strogatz SH. Modeling a synthetic multicellular clock: repressilators coupled by quorum sensing. Proc Natl Acad Sci U S A. 2004;101: 1095560. doi:10.1073/pnas.0307095101

39. Seaton DD, Ebenhöh O, Millar AJ, Pokhilko A. Regulatory principles and experimental approaches to the circadian control of starch turnover. J R Soc Interface. 2014;11:

40. Seaton DD, Smith RW, Song YH, MacGregor DR, Stewart K, Steel G, et al. Linked circadian outputs control elongation growth and flowering in response to photoperiod and temperature. Mol Syst Biol. 2015;11: 776. doi:10.15252/MSB.20145766

41. Shimizu H, Katayama K, Koto T, Torii K, Araki T, Endo M. Decentralized circadian clocks process thermal and photoperiodic cues in specific tissues. Nat Plants. 2015;1: 15163. doi:10.1038/nplants.2015.163

42. Meyerowitz EM. Genetic control of cell division patterns in developing plants. Cell. 1997;88: 299-308. doi:10.1016/S0092-8674(00)81868-1

43. Dawson GB, Fisher RG. Diurnal and seasonal ground temperature variations at Wairakei. New Zeal J Geol Geophys. 1964;7: 144-154. doi:10.1080/00288306.1964.10420166

44. Rellán-Álvarez R, Lobet G, Lindner H, Pradier P-L, Sebastian J, Yee M-C, et al. GLO-

Roots: an imaging platform enabling multidimensional characterization of soil-grown root

625 45. Bell-Pedersen D, Cassone VM, Earnest DJ, Golden SS, Hardin PE, Thomas TL, et al. Circadian rhythms from multiple oscillators: lessons from diverse organisms. Nat Rev 
46. Para A, Farré EM, Imaizumi T, Pruneda-Paz JL, Harmon FG, Kay SA. PRR3 Is a vascular regulator of TOC1 stability in the Arabidopsis circadian clock. Plant Cell. 2007;19: 3462-73. doi:10.1105/tpc.107.054775

631 47. Sokolove PG, Bushell WN. The chi square periodogram: Its utility for analysis of circadian rhythms. J Theor Biol. 1978;72: 131-160. doi:10.1016/0022-5193(78)90022-X

48. Pittayakanchit W, Lu Z, Chew J, Rust MJ, Murugan A. Biophysical clocks face a trade-off between internal and external noise resistance. Elife. 2018;7. doi:10.7554/eLife.37624

49. Gu L, Fuentes JD, Garstang M, Silva JT Da, Heitz R, Sigler J, et al. Cloud modulation of surface solar irradiance at a pasture site in Southern Brazil. Agric For Meteorol. 


\section{$654 \quad$ Figures}

A

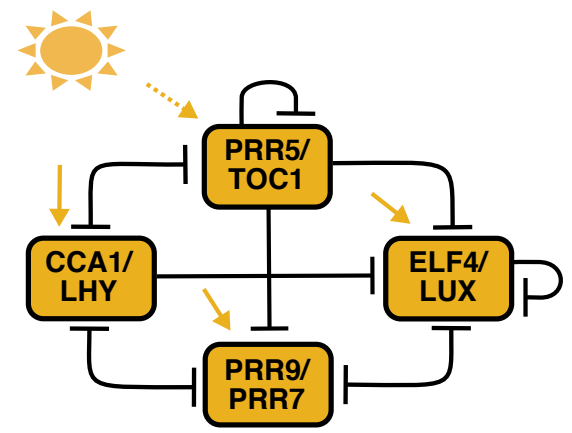

C

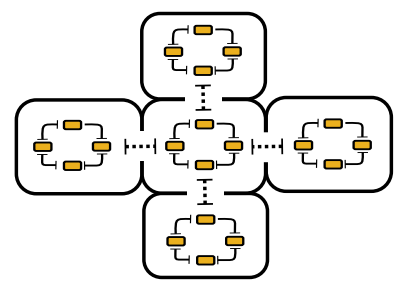

B

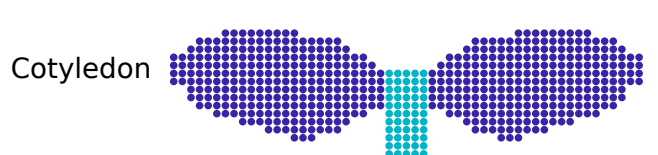

Hypocotyl

Root

Root tip
655

656

657

658

659

660

661

662

663

664

665

666

667

668

TOC1, TIMING OF CAB EXPRESSION 1.

Fig 1. The structure of the spatial circadian clock model. (A) Summary of the modified compact circadian clock model used for simulations. The original compact model [31] is modified to include a repression interaction between CCA1/LHY and PRR5/TOC1. Light input is received by all gene pairs, but affects their production and degradation rates to different degrees. Yellow dashed arrows represent light input at the transcriptional level and solid yellow arrows represent light input at both the transcriptional and post-transcription level. "T" arrows represent repression. (B) The network was implemented within each cell on a simplified template of a seedling, with cells classified as either cotyledon (blue), hypocotyl (turquoise), root (yellow), or root tip cells (green). (C) The network in each individual cell is coupled to the neighboring cells through the level of CCA1/LHY. CCA1, CIRCADIAN CLOCK ASSOCIATED 1; ELF4, EARLY FLOWERING 4; LHY, LATE ELONGATED HYPOCOTYL; LL, constant light; LUC, LUCIFERASE; LUX, LUX ARRHYTHMO; PRR, PSEUDO-RESPONSE REGULATOR; 
A

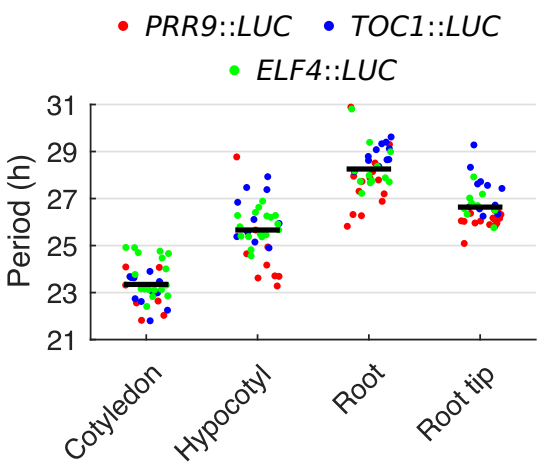

B

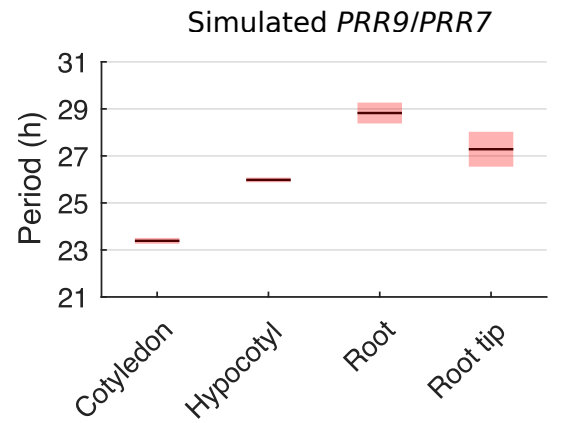

D

X Simulated PRR9/PRR7 X PRR9::LUC

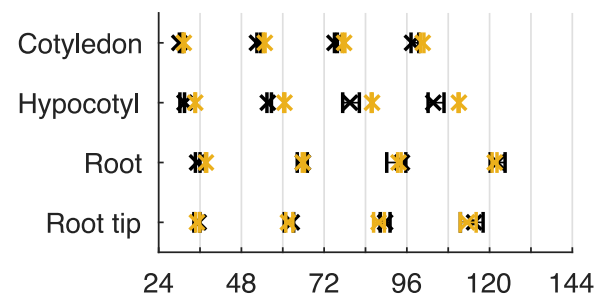

$\mathbf{F}$

X Simulated ELF4/LUX $\quad$ XEF4::LUC

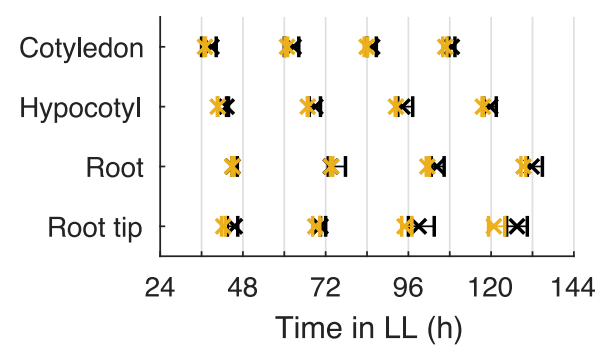

C
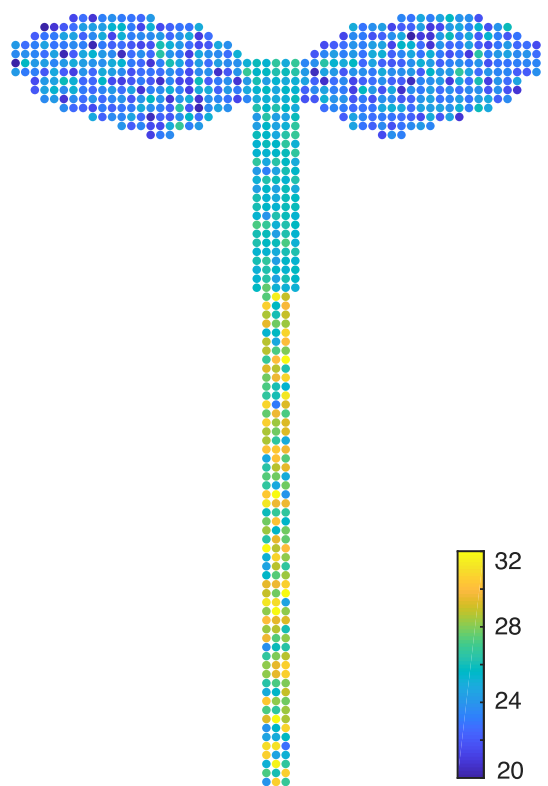

$\mathbf{E}$

$\times$ Simulated PRR5/TOC1 $\times$ TOC1::LUC

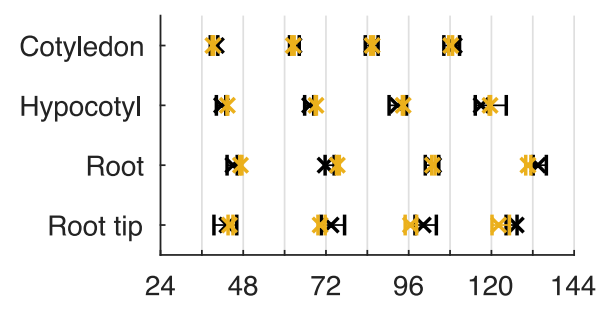

671

672 Fig 2. Regional differences in light input can generate the period structure observed

673 experimentally. (A) Period estimates of PRR9::LUC, TOC1::LUC, and ELF4::LUC for different

674 organs imaged under LL. Each data point represents a period estimate from the organ of a

675 single seedling. The horizontal black line shows the mean. (B) Period estimates of simulated 
PRR9/PRR7 expression, measured from regions within the template seedling. The black line

677 indicates the mean and the red shaded area one standard deviation of 18 independent

678 simulations. (C) Periods of individual cells plotted on the template seedling. The color of the cell

679 represents the speed of the oscillation. By assuming higher light input to the cells in the

680 cotyledon, hypocotyl, and root tip, the model approximates the period differences observed

681 between regions in experiments, A. A noise parameter was adjusted for each region to simulate

682 the variability of periods observed in single cell experiments (S1 Fig). (D-F) Times of peaks of

683 simulated PRR9/PRR7 and PRR9::LUC (D), simulated PRR5/TOC1 and TOC1::LUC (E), or

684 simulated ELF4/LUX and ELF4::LUC (F), in different organs under LL. Simulations include

685 different levels of light input to regions and cell-to-cell coupling $(J=2)$. Plots represent the 25th

686 percentile, median, and the 75th percentile for the peak times of oscillations scored as rhythmic,

$687 n=9$ simulations. Experimental data is an analysis of time-lapse movies carried out previously

688 [14]. CCA1, CIRCADIAN CLOCK ASSOCIATED 1; CV, coefficient of variation; ELF4, EARLY

689 FLOWERING 4; LHY, LATE ELONGATED HYPOCOTYL; LL, constant light; LUC,

690 LUCIFERASE; LUX, LUX ARRHYTHMO; PRR, PSEUDO-RESPONSE REGULATOR; TOC1,

691 TIMING OF CAB EXPRESSION 1.

692

693

694 
A

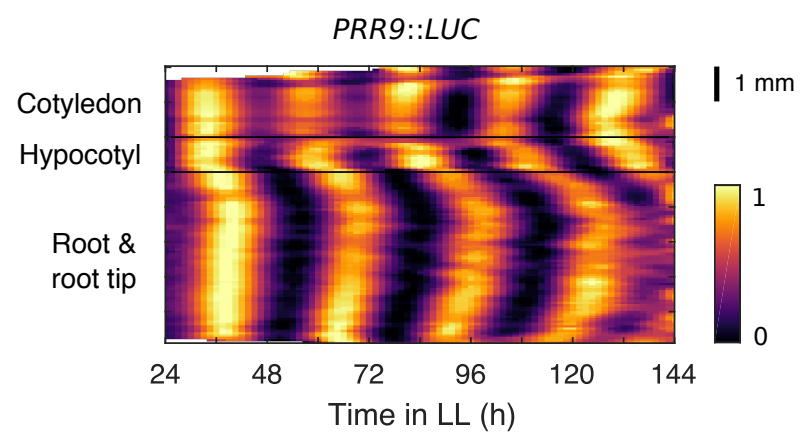

C

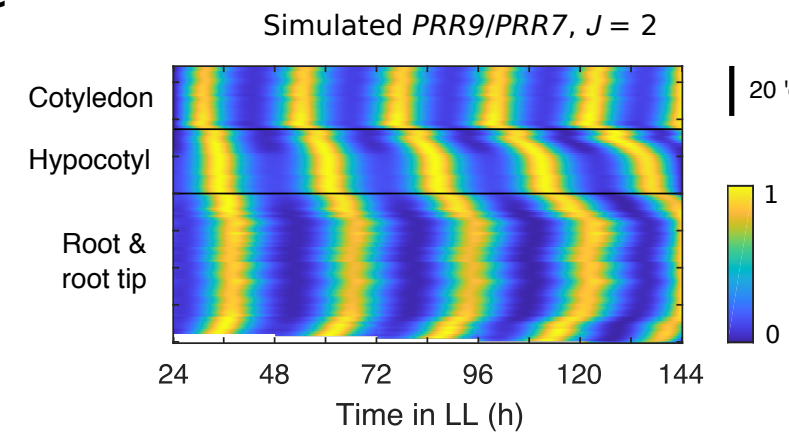

E

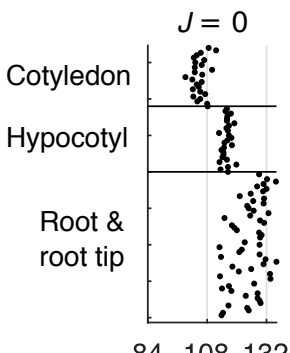

8410813284108132
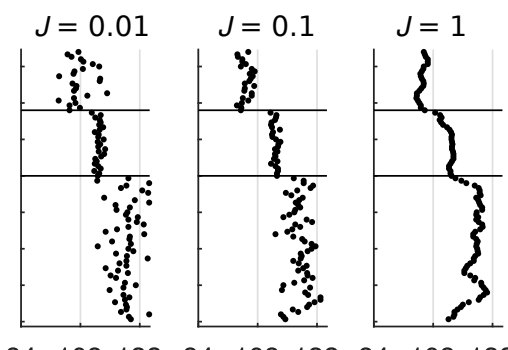

$84 \quad 108 \quad 13284 \quad 108132$

Time in LL (h)
B

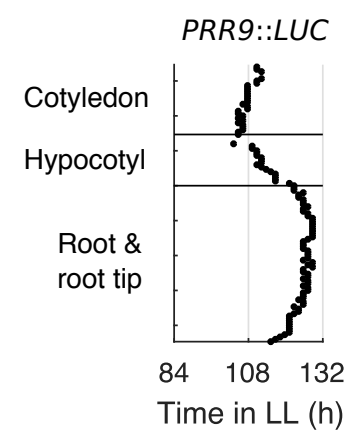

D

Simulated PRR9/7, $\mathrm{J}=2$
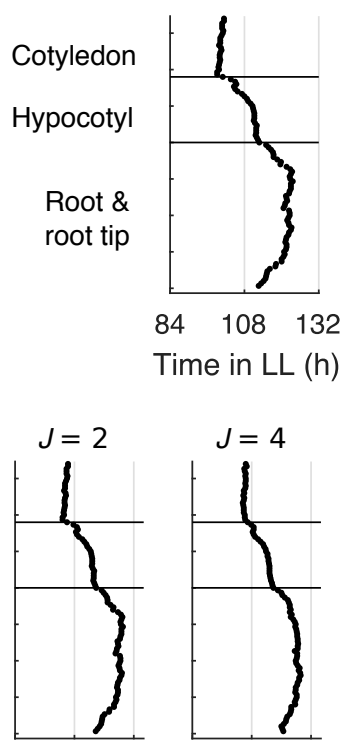

$\begin{array}{llllll}84 & 108 & 132 & 84 & 108 & 132\end{array}$

Fig 3. Local sharing of mRNA can reproduce experimentally observed spatial waves of PRR9::LUC intensity plot simulated under LL. (C) Representative intensity plot of simulated PRR9/PRR7 expression across longitudinal sections of a single seedling under LL. Simulations

701 include different levels of light input to regions and cell-to-cell coupling $(J=2)$. (D) Times of the

702 final peaks of the simulated $P R R 9 / P R R 7$ intensity plot simulated under LL. (E) Times of the final

703 peak of simulated $P R R 9 / P R R 7$ intensity plots, each simulated under LL with increasing strength

704 of coupling, J. Experimental data is an analysis of time-lapse movies carried out previously [14]. 
705 PRR, PSEUDO RESPONSE REGULATOR; LL, constant light; LUC, LUCIFERASE. TOC1,

706 TIMING OF CAB EXPRESSION 1.

707

708

709

710

711

712

713

714

715

716

717

718

719

720

721 
A

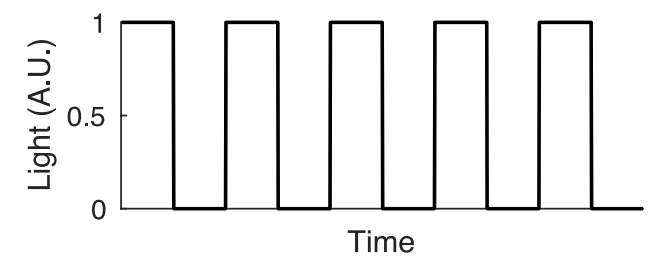

B

Fig 4. Regional phase differences persist under idealized and noisy LD cycles. (A)

724 Schematic of idealized LD cycles, without fluctuations in light levels during the daytime. (B)

725 Times of the final peak of simulated PRR5/TOC1 intensity plots, each simulated under idealized

726 LD with increasing strength of coupling, J. (C) Schematic of noisy LD cycles, with fluctuations in

727 light levels during the daytime. Each line represents an LD cycle for a single cell. (D) Times of

728 the final peak of simulated PRR5/TOC1 intensity plots, each simulated under noisy LD with

729 increasing strength of coupling, J. LD, light-dark; PRR, PSEUDO-RESPONSE REGULATOR;

730 TOC1, TIMING OF CAB EXPRESSION 1. 
A

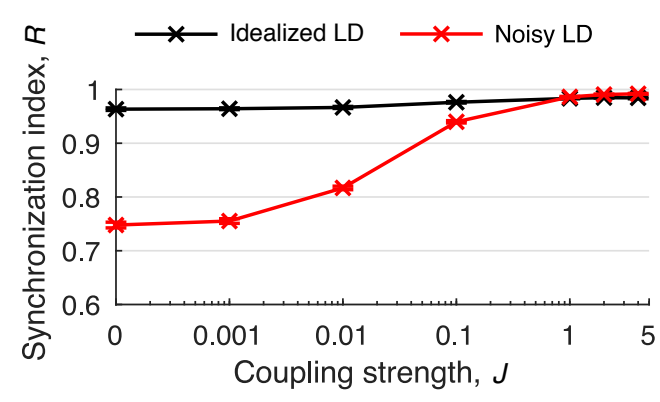

C

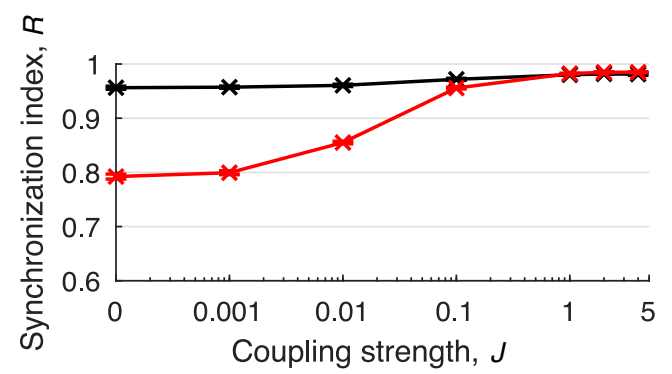

B

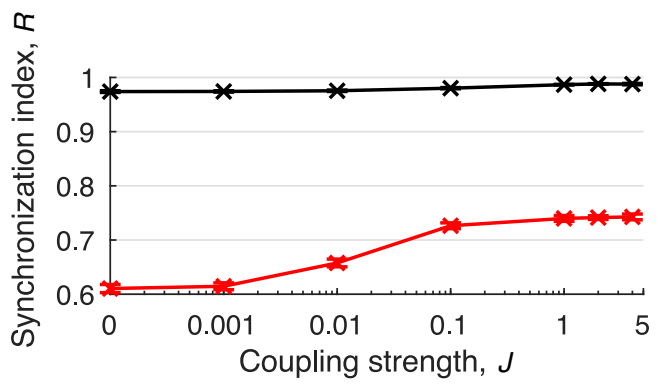

D

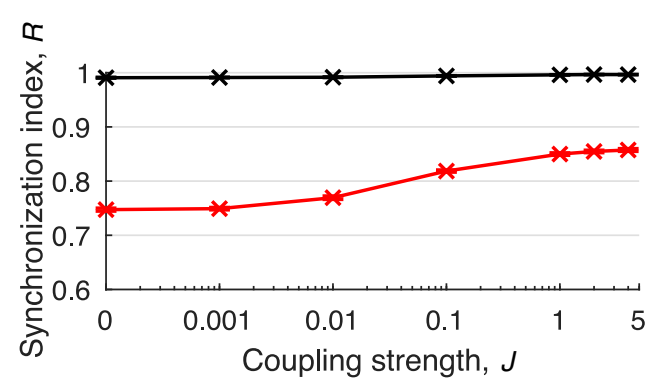

Fig 5. Cell-to-cell coupling maintains global synchrony under noisy LD cycles. (A-D)

736 Quantification of phase coherence by the synchronization index, $R$, for simulated CCA1/LHY

737 (A), PRR9/PRR7 (B), PRR5/TOC1 (C) or ELF4/LUX (D) mRNA expression under idealized or noisy LD cycles. Simulations included increasing strengths of coupling, J. Color legends are as in A. Data points represent the mean \pm standard deviation, $n=9$ simulations. CCA1, 


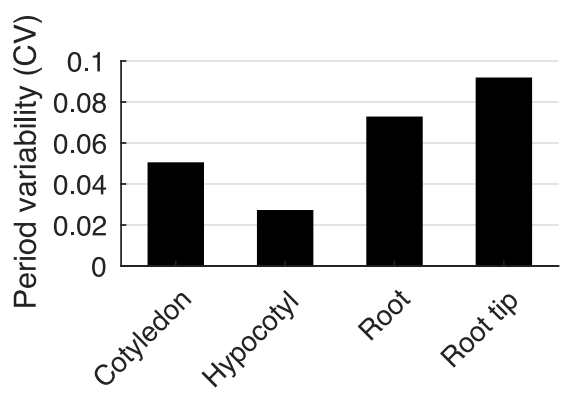

750 S1 Fig. Between-cell variability of CCA1-YFP rhythms. Between-cell variability of periods

751 within different organs. The periods were estimated from single cell time-lapse movies of CCA1-

752 YFP expression carried out previously [8]. CCA1, CIRCADIAN CLOCK ASSOCIATED 1; CV,

753 coefficient of variation; YFP, yellow fluorescent protein. 

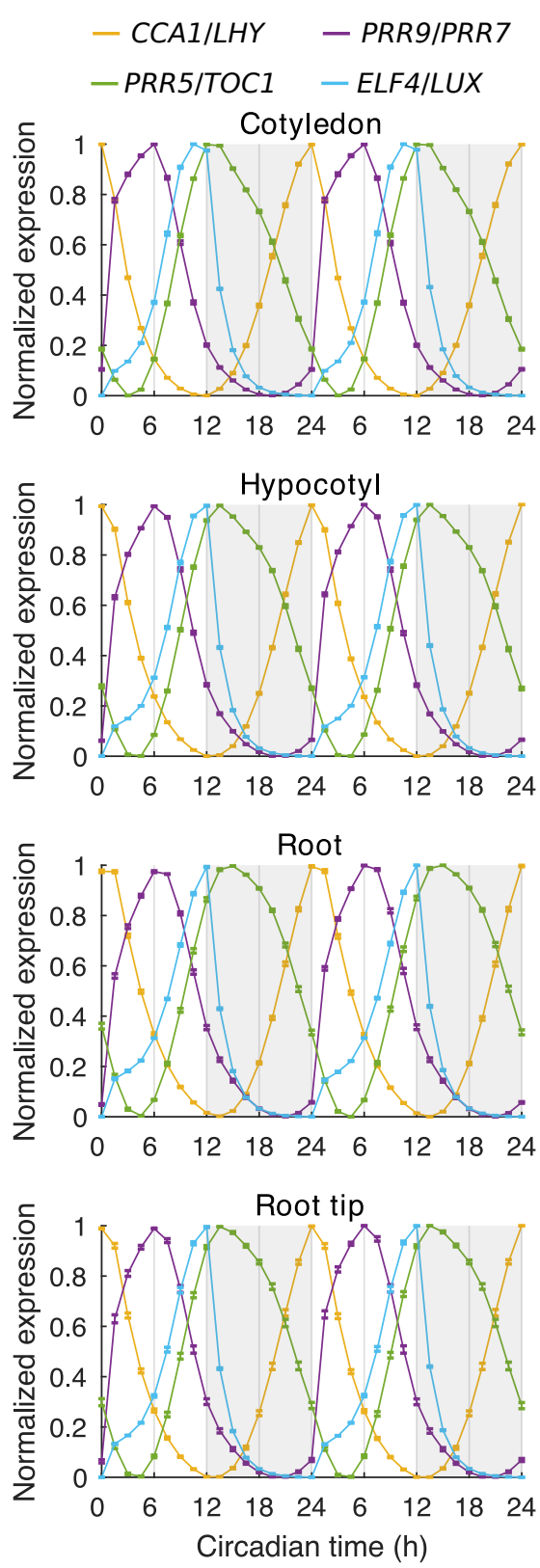

756 S2 Fig. Simulated expression of clock genes in different regions under LD cycles.

757 Expression of simulated CCA1/LHY, PRR9/PRR7, PRR5/TOC1, and ELF4/LUX from regions of

758 the seedling template 96-144 $\mathrm{h}$ after the beginning of LD cycles. The light input, $L$, was varied

759 depending on whether the cell was within the cotyledon $(L=1.35)$, hypocotyl $(L=1.10)$, $\operatorname{root}(L$

$760=0.90)$, or root tip $(L=1.03)$ region, and coupling was present between cells $(J=2)$. Data

761 represent the mean \pm standard error, $n=9$ simulations. CCA1, CIRCADIAN CLOCK

762 ASSOCIATED 1; ELF4, EARLY FLOWERING 4; LD, light-dark; LHY, LATE ELONGATED 
764 REGULATOR; TOC1, TIMING OF CAB EXPRESSION 1.

765

766

767

768

769

770

771

772

773

774

775

776

777

778

779

780

781

782

783

784 
A
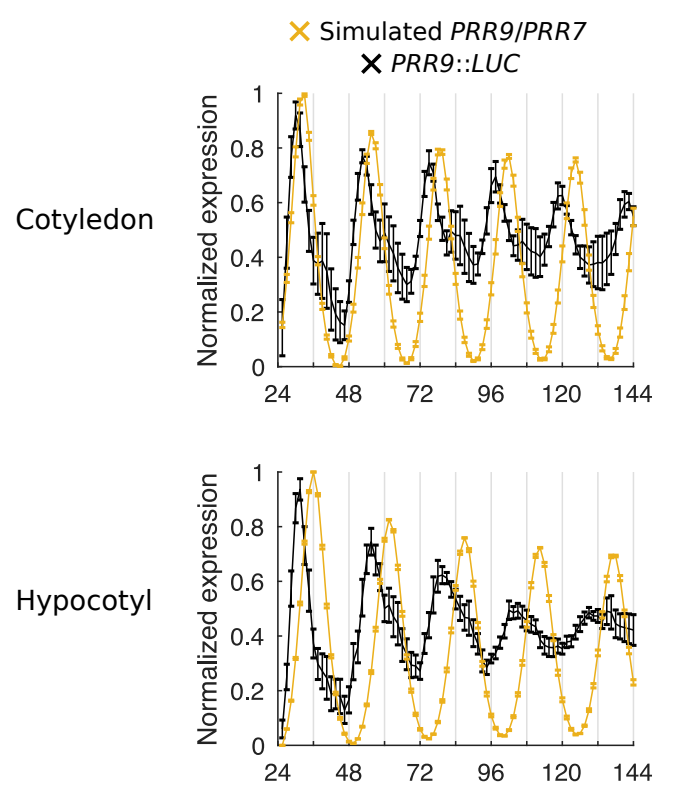

Root

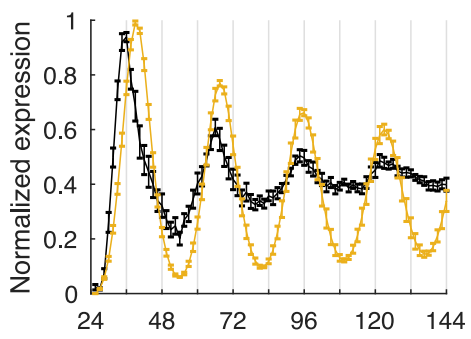

Root tip

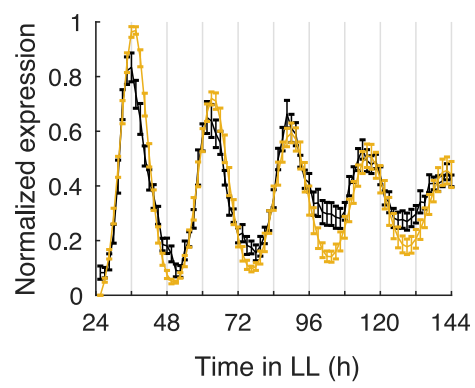

B
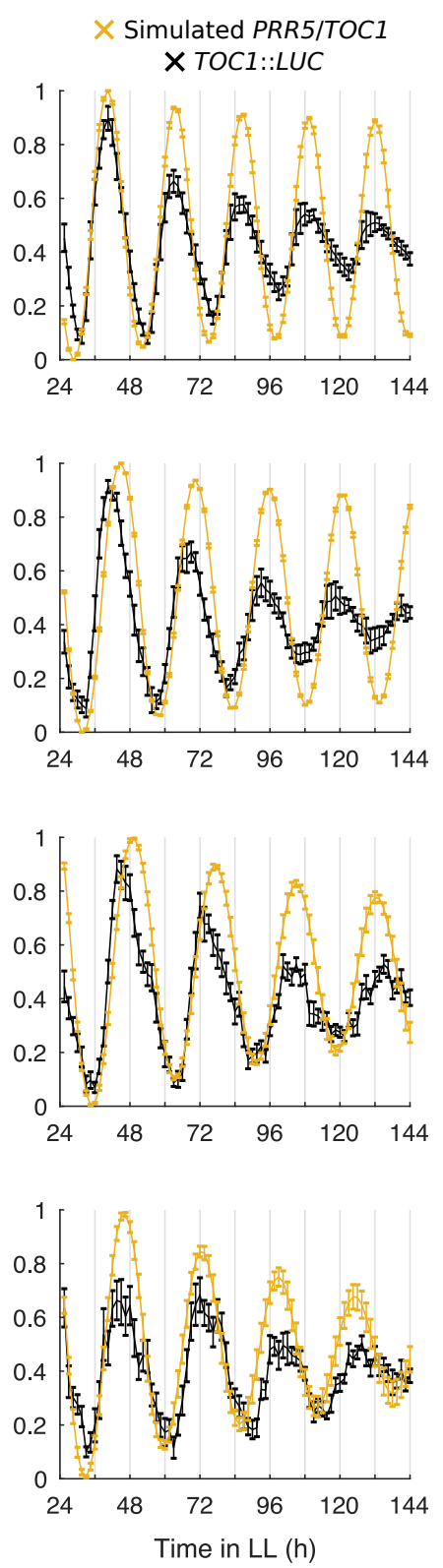

C
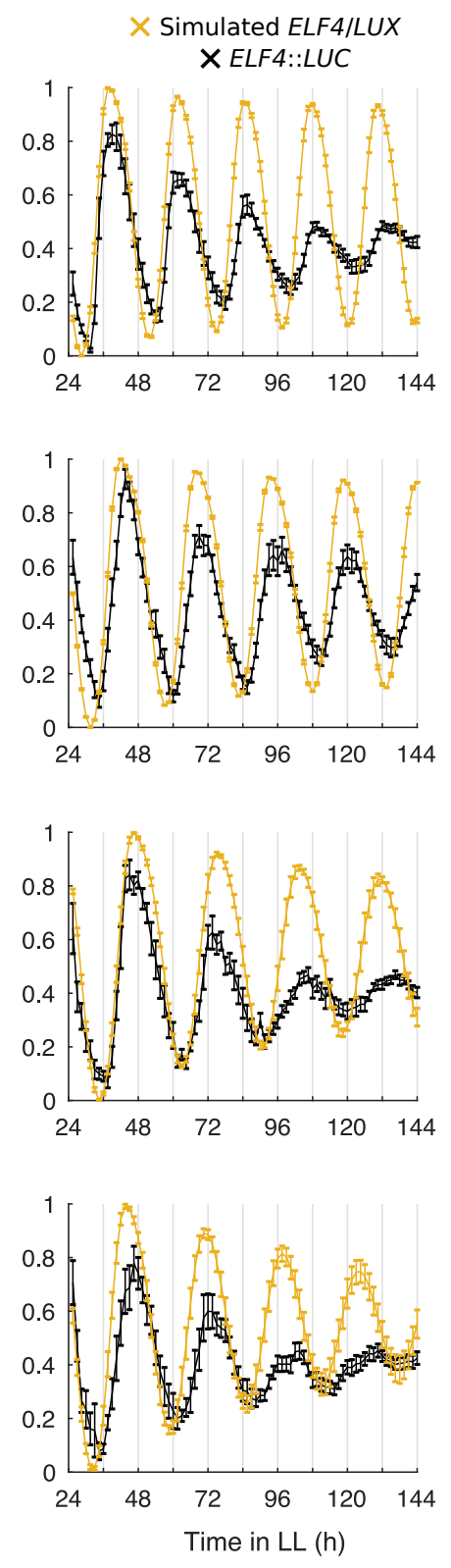

S3 Fig. Simulated expression of multiple core clock genes under LL qualitatively match

luciferase reporter experiments. (A-C) Expression of simulated PRR9/PRR7 and PRR9::LUC

788 (A), simulated PRR5/TOC1 and TOC1::LUC (B), or simulated ELF4/LUX and ELF4::LUC (C) in

789 different organs under LL. Simulations include different levels of light input to regions and cell-

790 to-cell coupling $(J=2)$. Data represent the mean \pm standard error of organs scored as rhythmic.

$791 n=9$ simulations. Experimental data is from time-lapse movies carried out previously [14]. 
792 ELF4, EARLY FLOWERING 4; LL, constant light; LUC, LUCIFERASE; LUX, LUX

793 ARRHYTHMO; PRR, PSEUDO-RESPONSE REGULATOR; TOC1, TIMING OF CAB

794 EXPRESSION 1.

795

796

797

798

799

800

801

802

803

804

805

806

807

808

809

810

811

812

813

814

815 


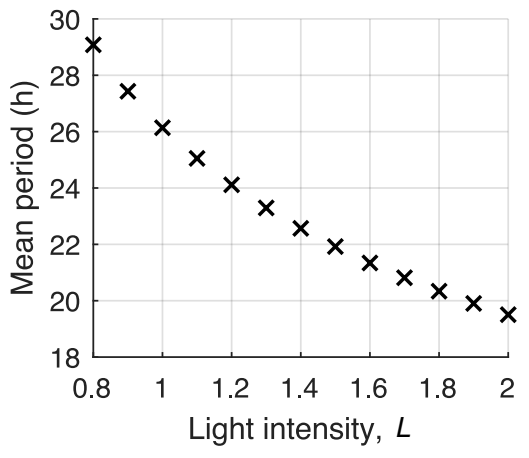

817 S4 Fig. Higher light intensities cause simulations to run faster. The mean peak-to-peak

818 time of simulated PRR9/PRR7 expression with increasing intensities of light, L. A single

819 instance of the model was implemented at each $L$, without cell-to-cell coupling or variation in

820 gene expression. $L$ values below 0.8 caused damping in the original and modified De Caluwe

821 implementation. PRR, PSEUDO-RESPONSE REGULATOR. 
A

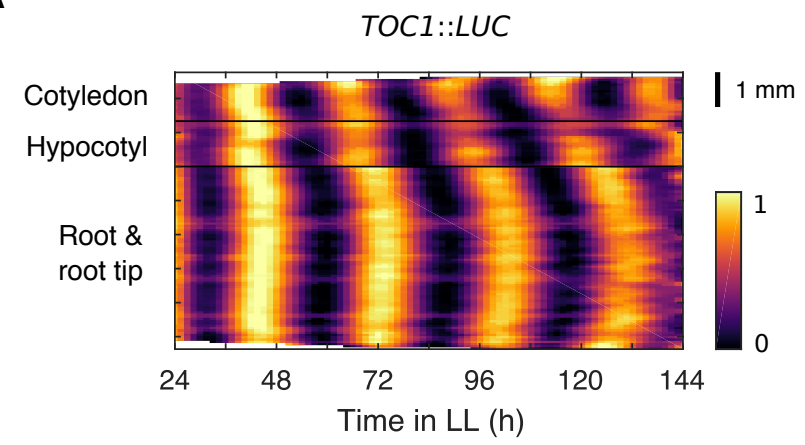

B

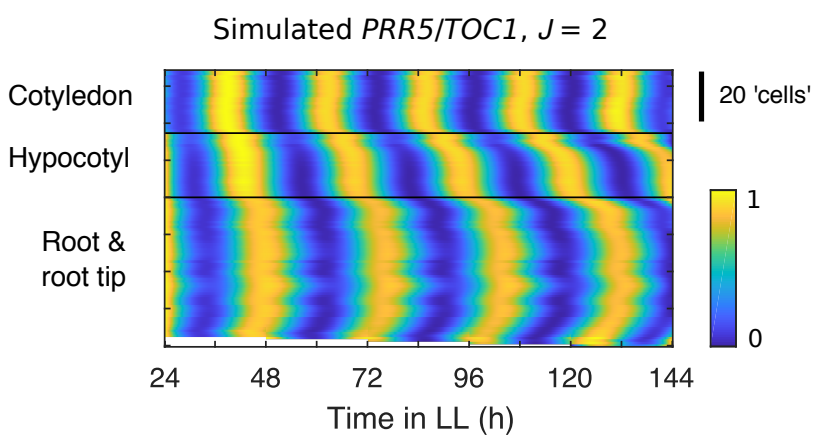

C

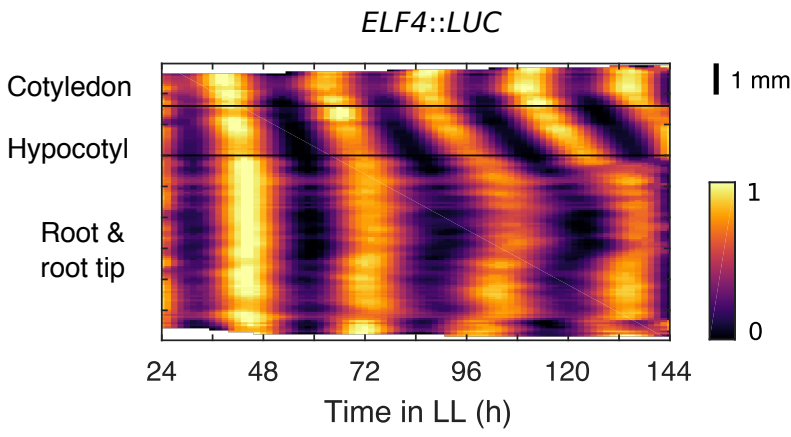

D

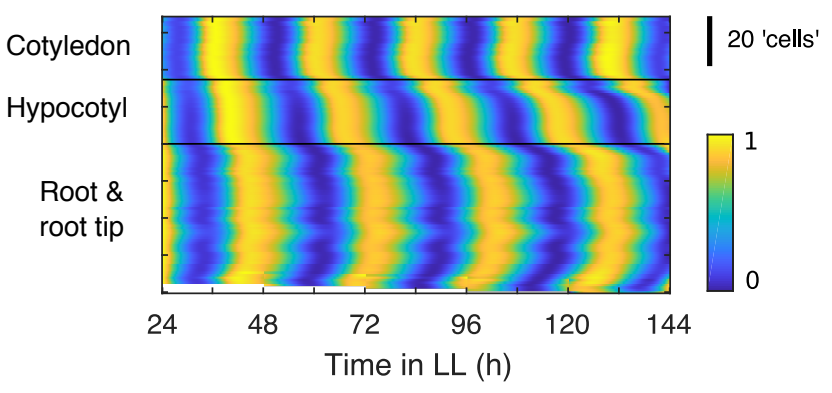

E

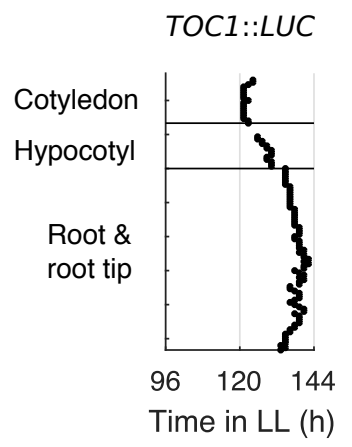

$\mathbf{F}$

Simulated PRR5/TOC1

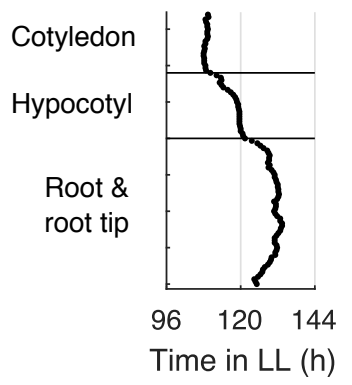

G

$$
\text { ELF4::LUC }
$$

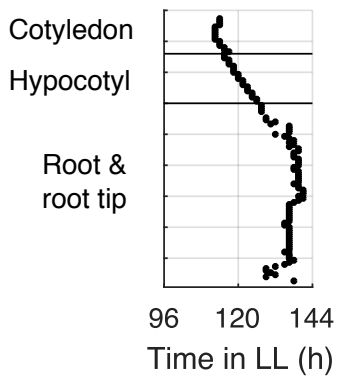

H

Simulated ELF4/LUX

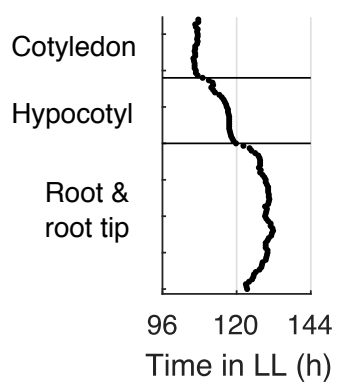

S5 Fig. Local sharing of mRNA can reproduce experimentally observed spatial waves of clock gene expression for multiple core clock genes. (A-D) Representative intensity plot of TOC1::LUC (A), simulated PRR5/TOC1 (B), ELF4::LUC (C) and simulated ELF4/LUX (D) expression across longitudinal sections of a single seedling under LL. Simulations include 
836 different levels of light input to regions and cell-to-cell coupling $(J=2)$. $(E-H)$ Times of the final

837 peak of TOC1::LUC (E), simulated PRR5/TOC1 (F), ELF4::LUC (G) and simulated ELF4/LUX

$838(\mathrm{H})$ intensity plots. Experimental data is an analysis of time-lapse movies carried out previously

839 [14]. ELF4, EARLY FLOWERING 4; LHY, LATE ELONGATED HYPOCOTYL; LL, constant light;

840 LUX, LUX ARRHYTHMO; PRR5, PSEUDO-RESPONSE REGULATOR 5; TOC1, TIMING OF

841 CAB EXPRESSION 1.

842

843

844

845

846

847

848

849

850

851

852

853

854

855

856

857 
bioRxiv preprint dol: https://doi.org/10.1101/2020.09.13.294785; this version posted September 24, 2020. The copyright holder for this preprint (which was not certified by peer review) is the author/funder. All rights reserved. No reuse allowed without permission.

A

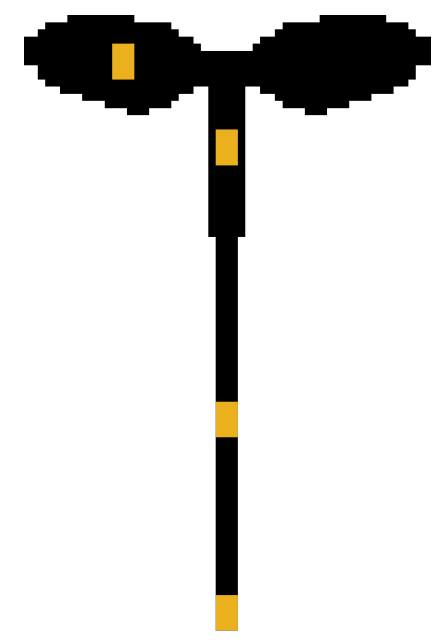

B

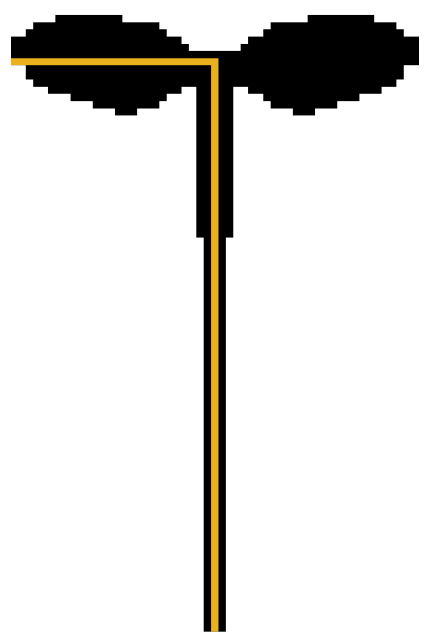

858

859 S6 Fig. Spatial analysis of rhythms across the simplified template of a plant. (A) To

860 measure the period and phase of an organ, the expression was extracted from 3-by-3 pixel

861 regions of interest (yellow squares). (B) To produce space-time plots of gene expression (e.g.

862 Fig 3A), the mean expression of sections perpendicular across the central axis (yellow line) of 863 the template were taken. Luciferase space-time plots were created similarly, as described 864 previously [14] (Methods).

865

866

867

868

869

870

871

872

873

42 
$\mathbf{A}$
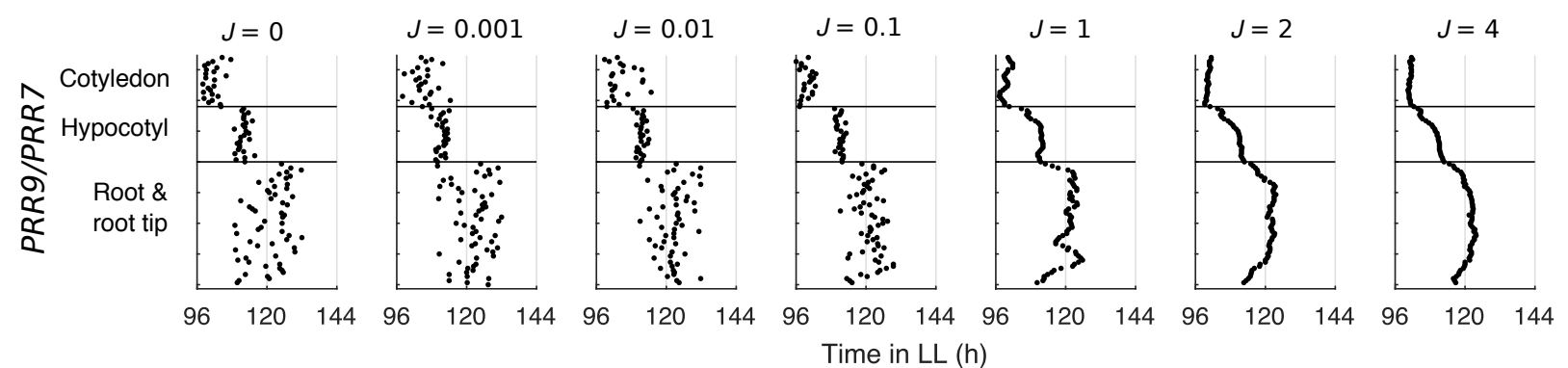

B
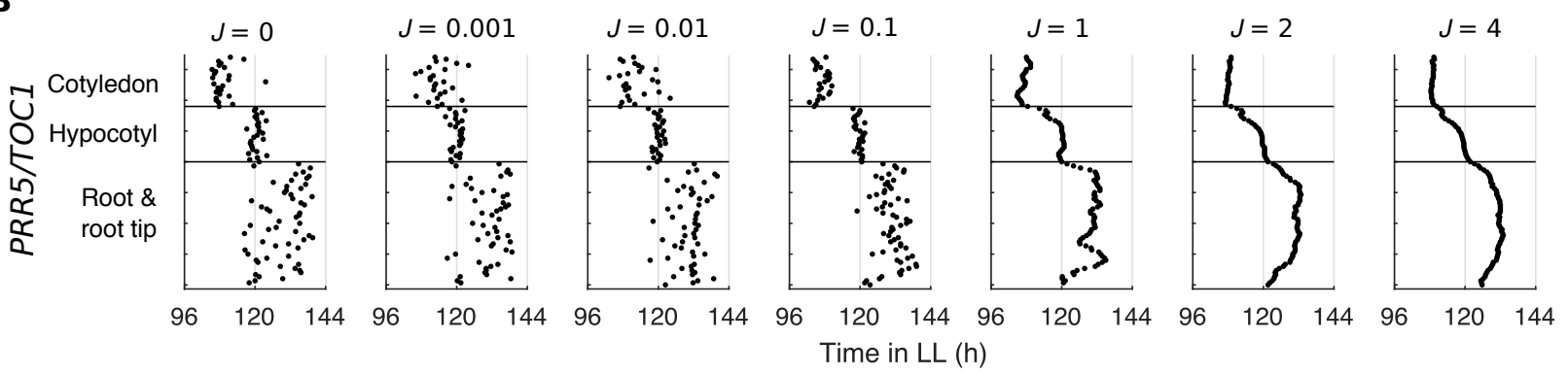

C
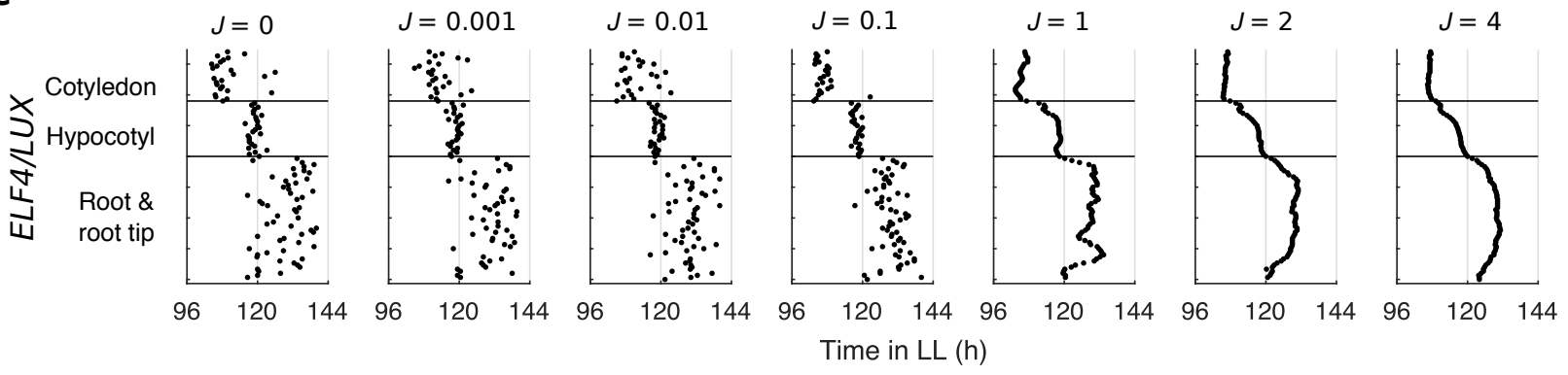

S7 Fig. Times of the final peaks of simulated expression under LL with increasing

strengths of coupling. (A-C) Times of the final peak of simulated $P R R 9 / P R R 7(\mathrm{~A})$, simulated

PRR5/TOC1 (B), and simulated ELF4/LUX (C) intensity plots, each simulated under LL with

878 increasing strength of coupling, J. ELF4, EARLY FLOWERING 4; LL, constant light; LUX, LUX 
$\mathbf{A}$
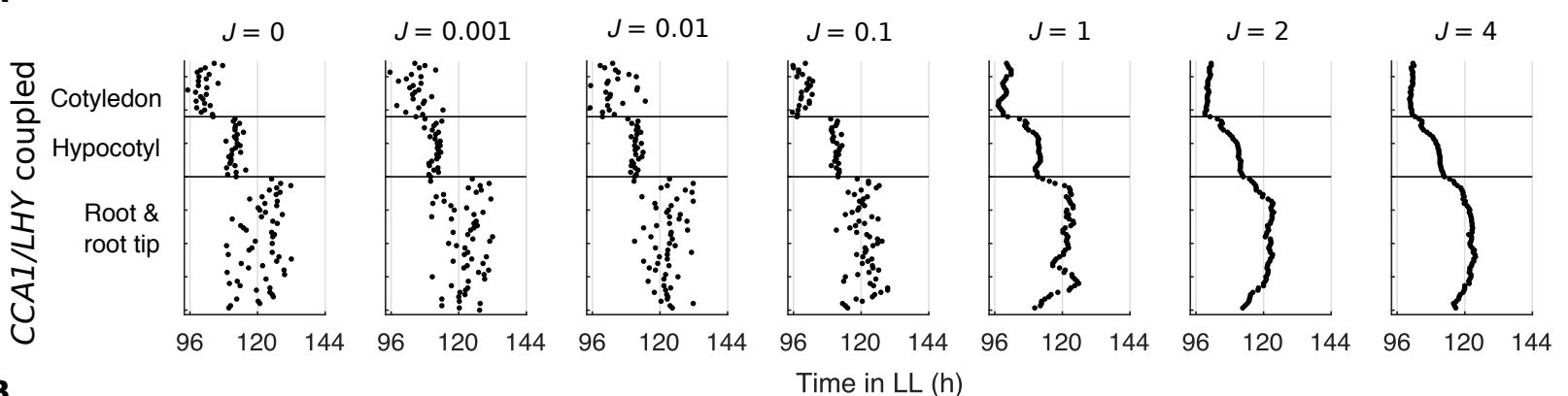

B
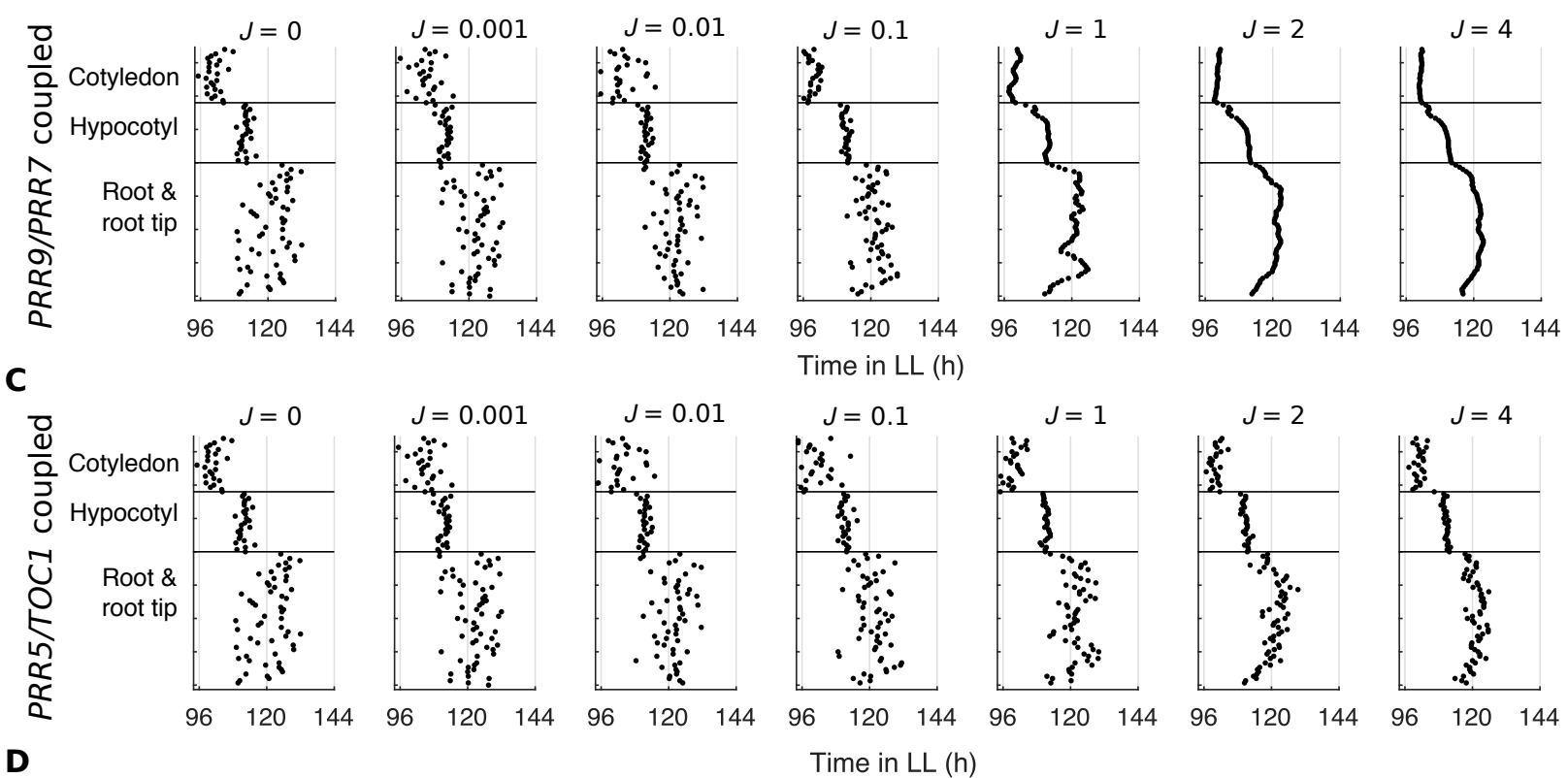

D
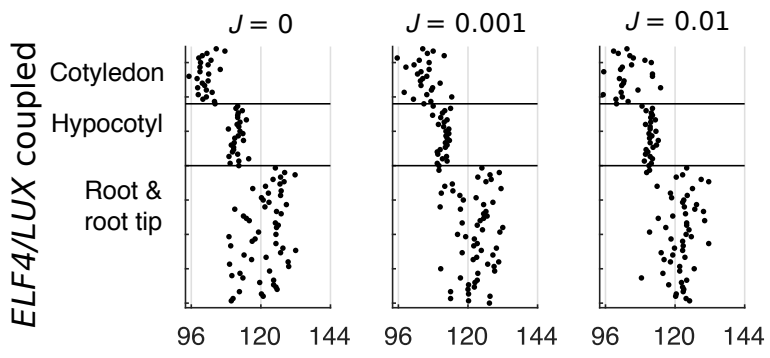

Time in LL $(\mathrm{h})$
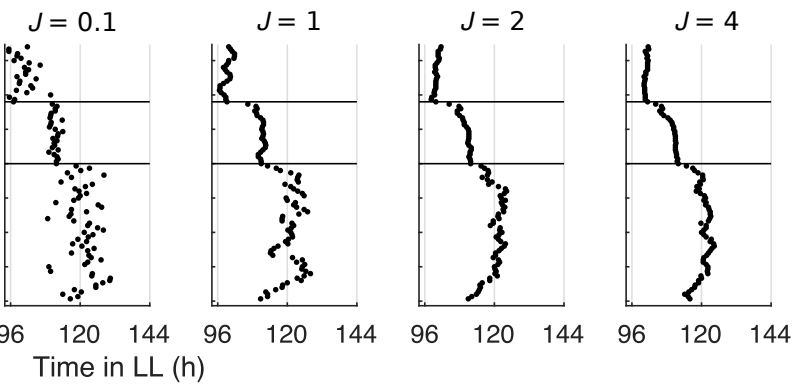

S8 Fig. Times of the final peaks of simulated expression under LL with the sharing of

887 different clock gene mRNA between cells. $(A-C)$ Times of the final peak of simulated

$888 P R R 9 / P R R 7$ intensity plots, each simulated with the sharing of CCA1/LHY, PRR9/PRR7,

889 PRR5/TOC1, or ELF4/LUX mRNA between neighbor cells. Simulations were under LL with

890 increasing strength of coupling, J. CCA1, CIRCADIAN CLOCK ASSOCIATED 1; ELF4, EARLY

891 FLOWERING 4; LHY, LATE ELONGATED HYPOCOTYL; LL, constant light; LUX, LUX 
893 EXPRESSION 1.

894

895

896

897

898

899

900

901

902

903

904

905

906

907

908

909

910

911

912

913

914

915 
A
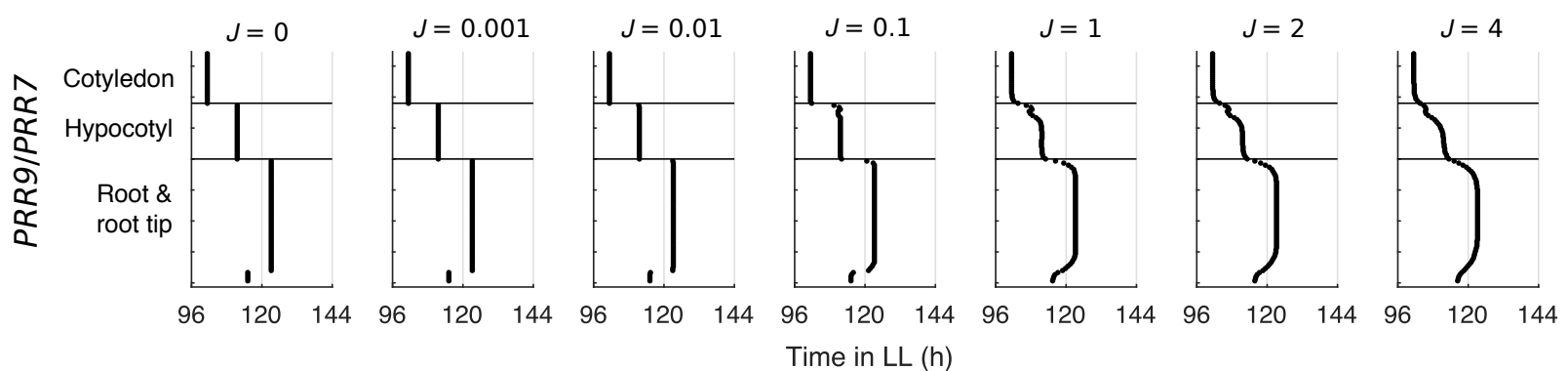

B
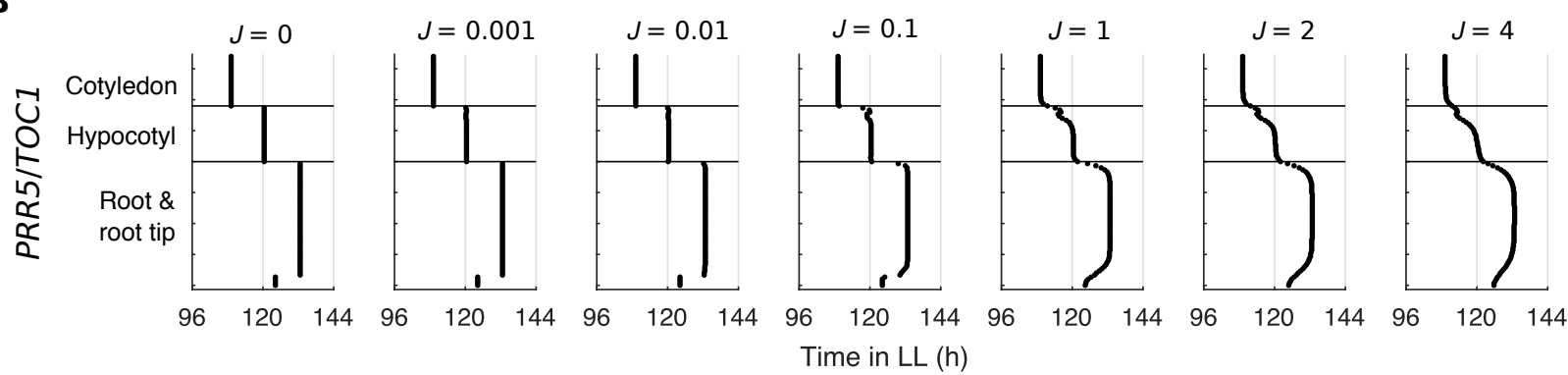

C
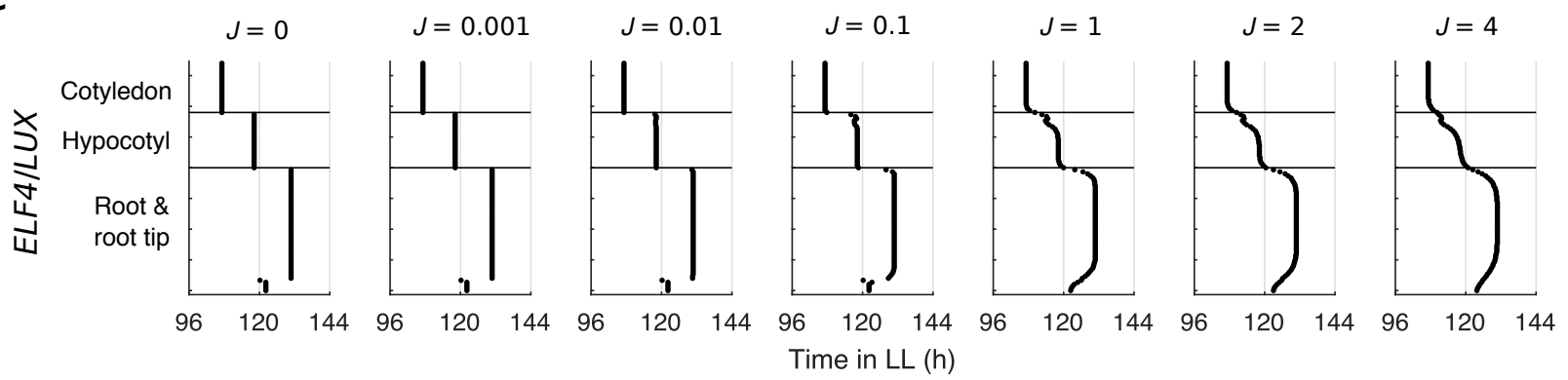

S9 Fig. Times of the final peaks of simulated expression under LL without variation in gene expression. (A-C) Times of the final peak of simulated PRR9/PRR7 (A), PRR5/TOC1 (B), or ELF4/LUX (C) intensity plots, each simulated with the sharing of CCA1/LHY mRNA

920 between 4 neighbor cells, but without cell-to-cell variation in gene expression. Simulations were

921 under LL with increasing strength of coupling, J. CCA1, CIRCADIAN CLOCK ASSOCIATED 1;

922 ELF4, EARLY FLOWERING 4; LHY, LATE ELONGATED HYPOCOTYL; LL, constant light;

923 LUX, LUX ARRHYTHMO; PRR, PSEUDO-RESPONSE REGULATOR; TOC1, TIMING OF CAB

\section{EXPRESSION 1.}


$\mathbf{A}$
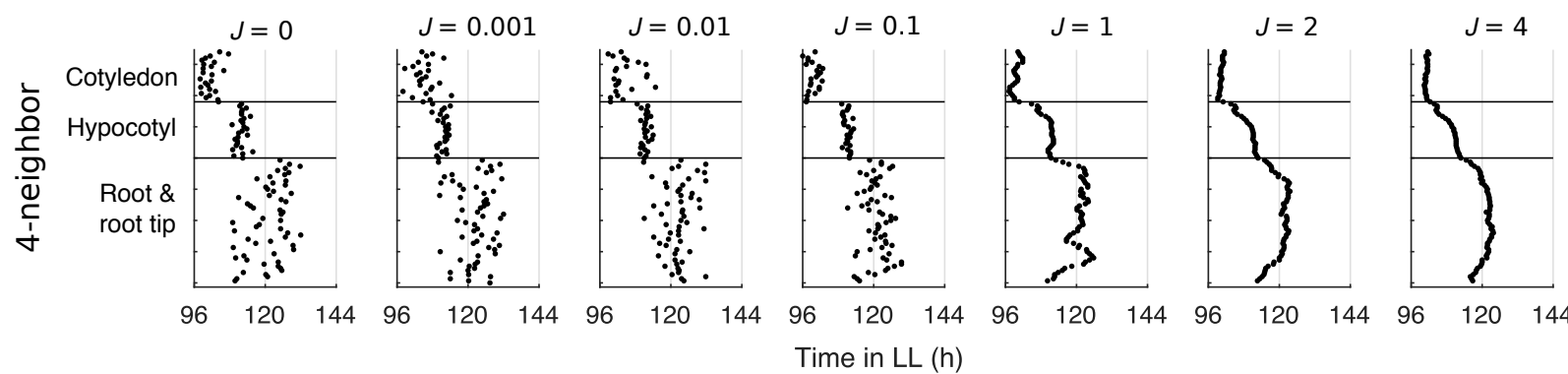

B
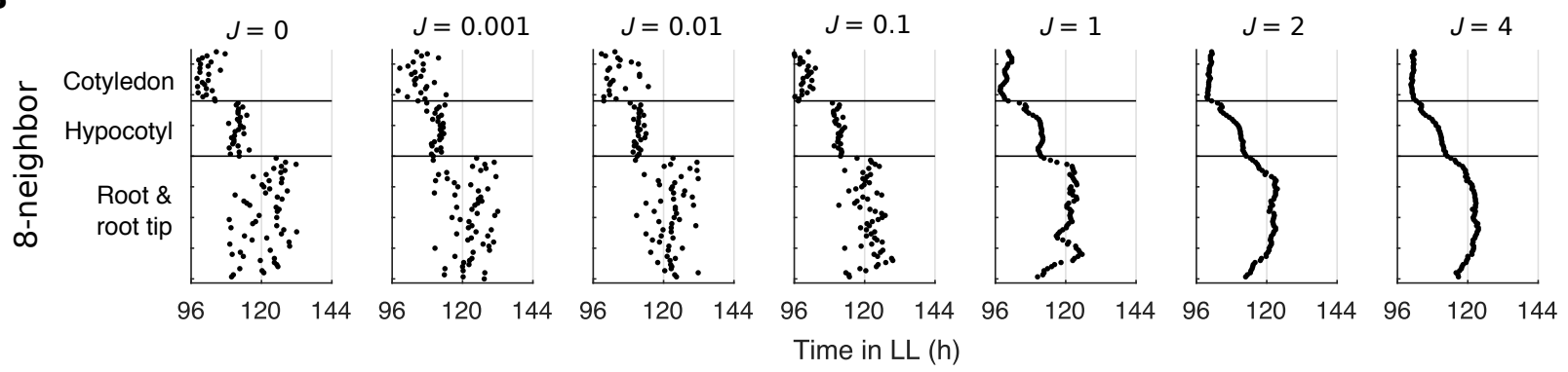

C
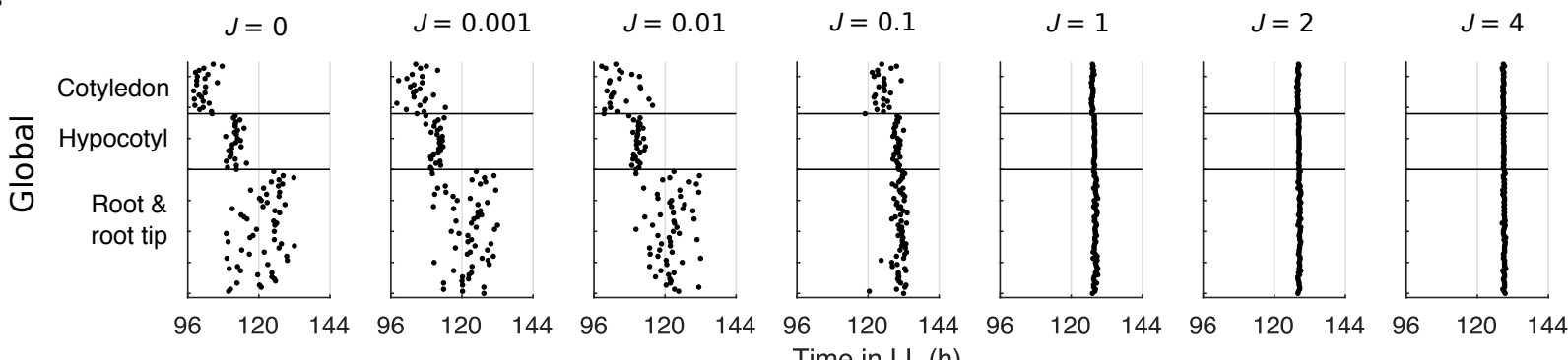

S10 Fig. Times of the final peaks of simulated expression under LL with different

928 coupling rules. $(\mathrm{A}-\mathrm{C})$ Times of the final peak of simulated $P R R 9 / P R R 7$ intensity plots, each simulated under LL with the sharing of CCA1/LHY mRNA between the 4 nearest neighbor cells (A), 8 nearest neighbor cells (B), or globally (all-to-all) (C). Simulations were run under LL with increasing strength of coupling, J. CCA1, CIRCADIAN CLOCK ASSOCIATED 1; LHY, LATE ELONGATED HYPOCOTYL; LL, constant light; PRR, PSEUDO-RESPONSE REGULATOR. 
A

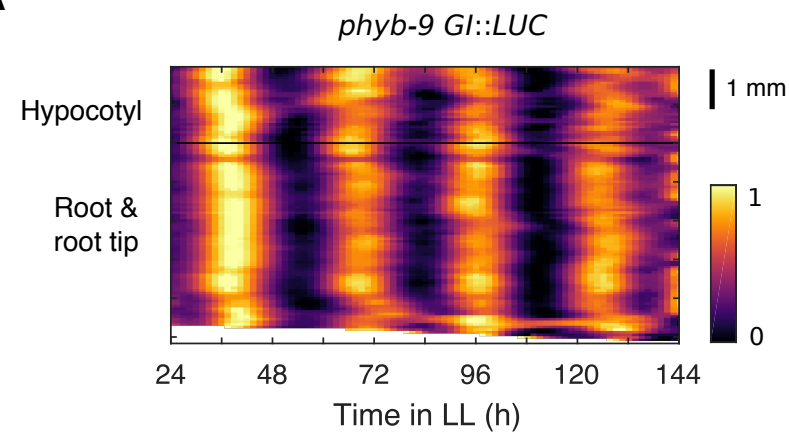

B

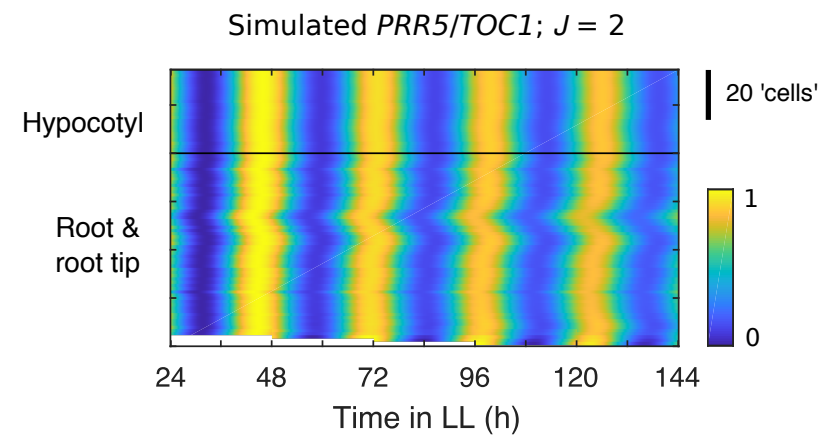

C

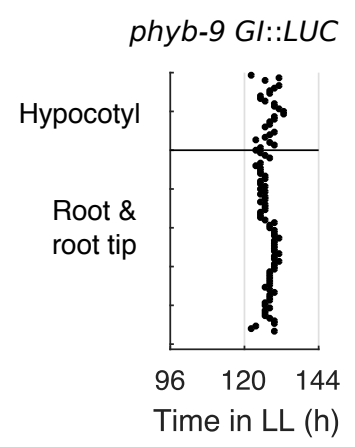

Simulated PRR5/ TOC1

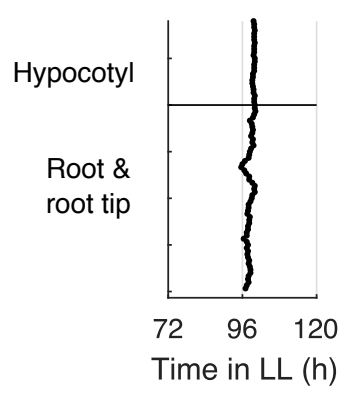

938 S11 Fig. Simulations with equal light input to regions predicts the loss of spatial waves

939 observed in the phyb-9 mutant. (A) Representative intensity plot of Gl::LUC expression

940 across longitudinal sections of a single seedling under constant red light. Imaging was

941 performed in the light sensing mutant phyb-9 background. (B) Representative intensity plot of

942 simulated PRR5/TOC1 expression across longitudinal sections of a single seedling under LL.

943 Simulations were performed with equal low light to all regions $(L=0.85)$ and cell-to-cell coupling

$944(J=2) .(C)$ Times of the final peaks of phyb-9 TOC1::LUC intensity plots. (D) Times of the final

945 peaks of simulated $P R R 5 / T O C 1$ intensity plots, with equal low light to all regions $(L=0.85)$ and

946 cell-to-cell coupling $(J=2)$. Experimental data is an analysis of time-lapse movies carried out

947 previously [14]. Intensity plots are limited to the lower hypocotyl and root due to rapid elongation

948 of the hypocotyl in the phyb-9 mutant. PRR, PSEUDO RESPONSE REGULATOR; LL, constant

949 light; LUC, LUCIFERASE. TOC1, TIMING OF CAB EXPRESSION 1. 
$\mathbf{A}$
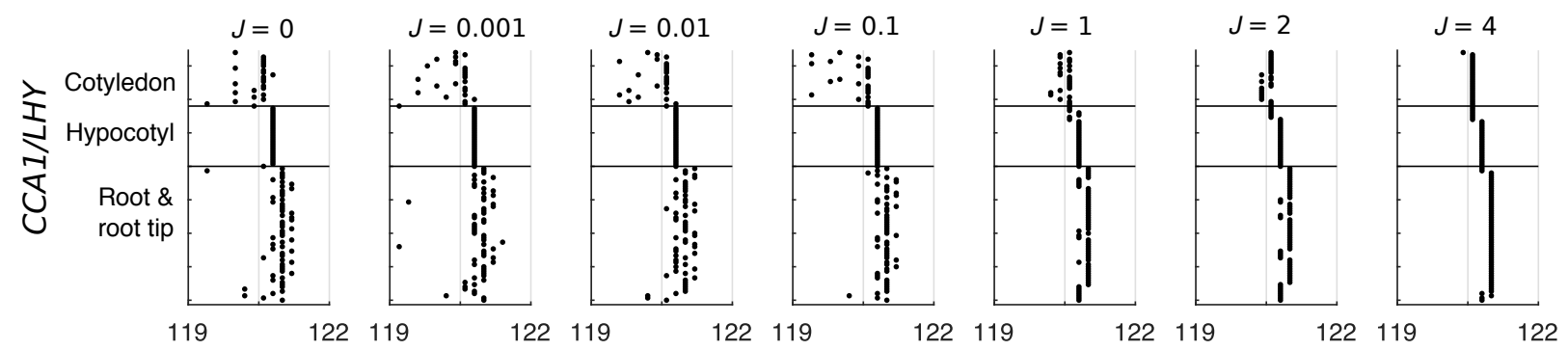

$\mathbf{B}$
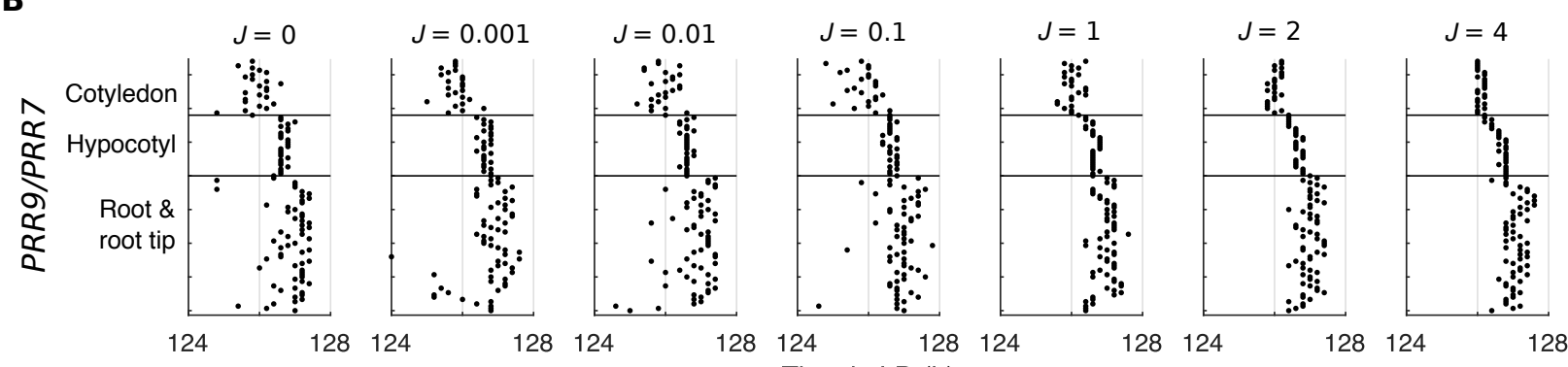

C
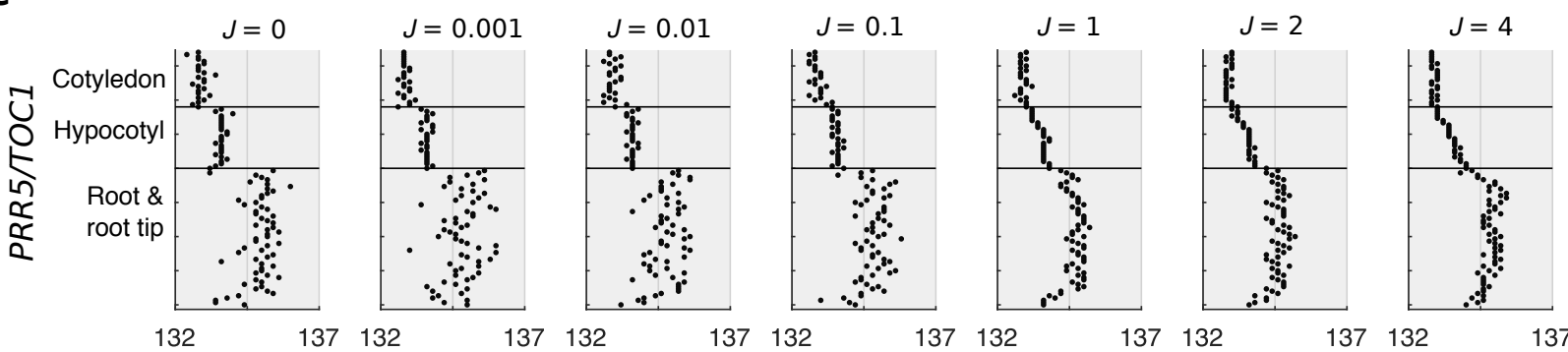

D
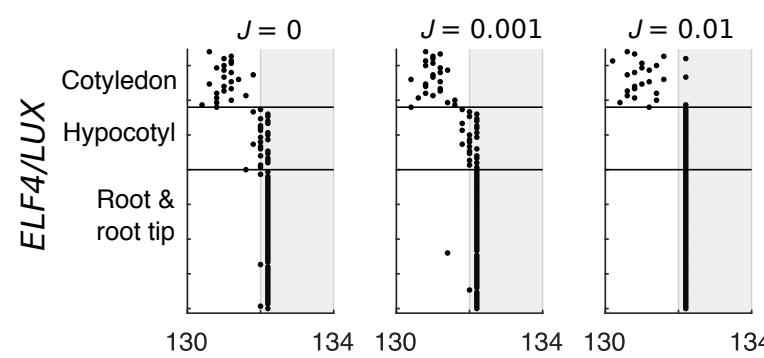

Time in LD $(\mathrm{h})$
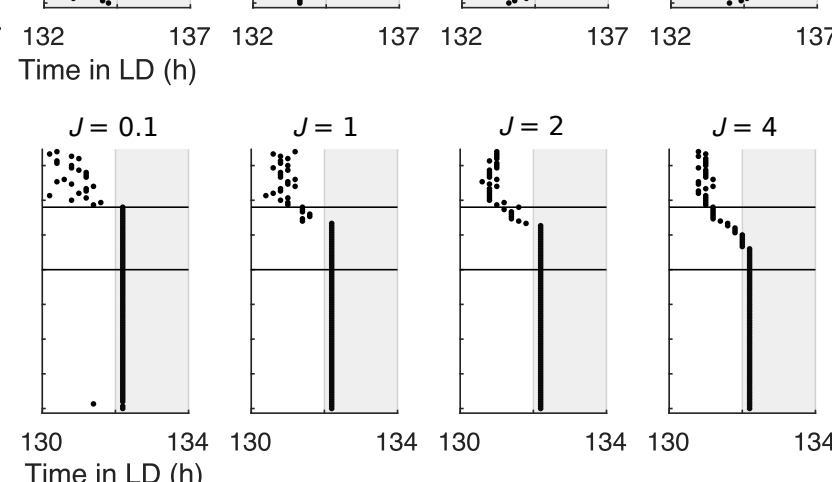

S12 Fig. Times of the final simulated peaks of expression under idealized LD cycles with

954 increasing strengths of coupling. (A-D) Times of the final peak of simulated CCA1/LHY (A),

$955 P R R 9 / P R R 7$ (B), PRR5/TOC1 (C), and ELF4/LUX (D) intensity plots, each simulated under

956 idealized LD cycles with increasing strength of coupling, J. Cells were exposed to idealized LD

957 cycles during simulations. Grey background indicates nighttime. ELF4 appears synchronized 
958 when the peak coincides with the dark transition as darkness causes strong repression of ELF4

959 expression. CCA1, CIRCADIAN CLOCK ASSOCIATED 1; ELF4, EARLY FLOWERING 4; LD,

960 light-dark; LHY, LATE ELONGATED HYPOCOTYL; LUX, LUX ARRHYTHMO; PRR, PSEUDO

961 RESPONSE REGULATOR; TOC1, TIMING OF CAB EXPRESSION 1.

962

963

964

965

966

967

968

969

970

971

972

973

974

975

976

977

978

979 
$\mathbf{A}$
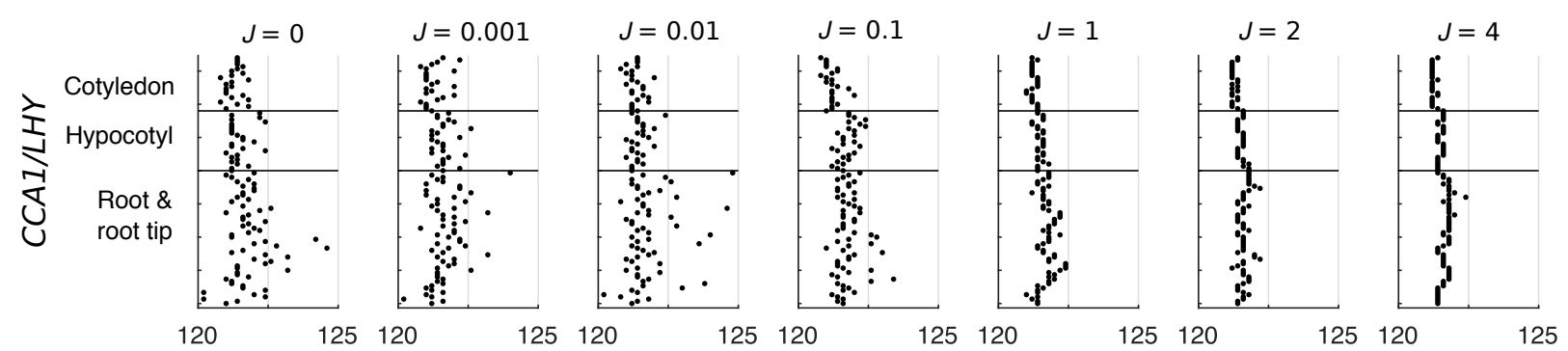

$\mathbf{B}$
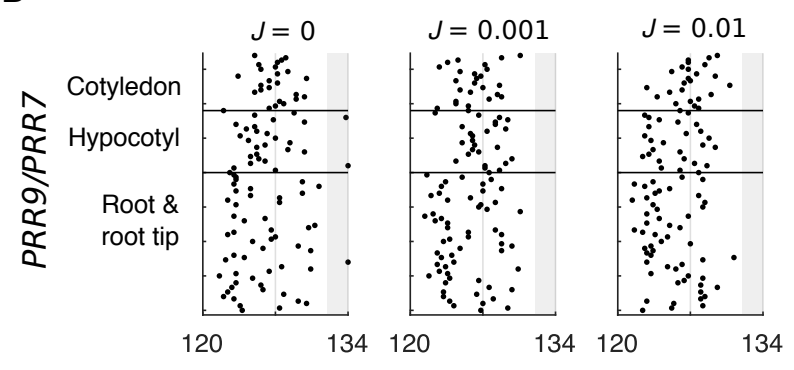

Time in LD (h)

C
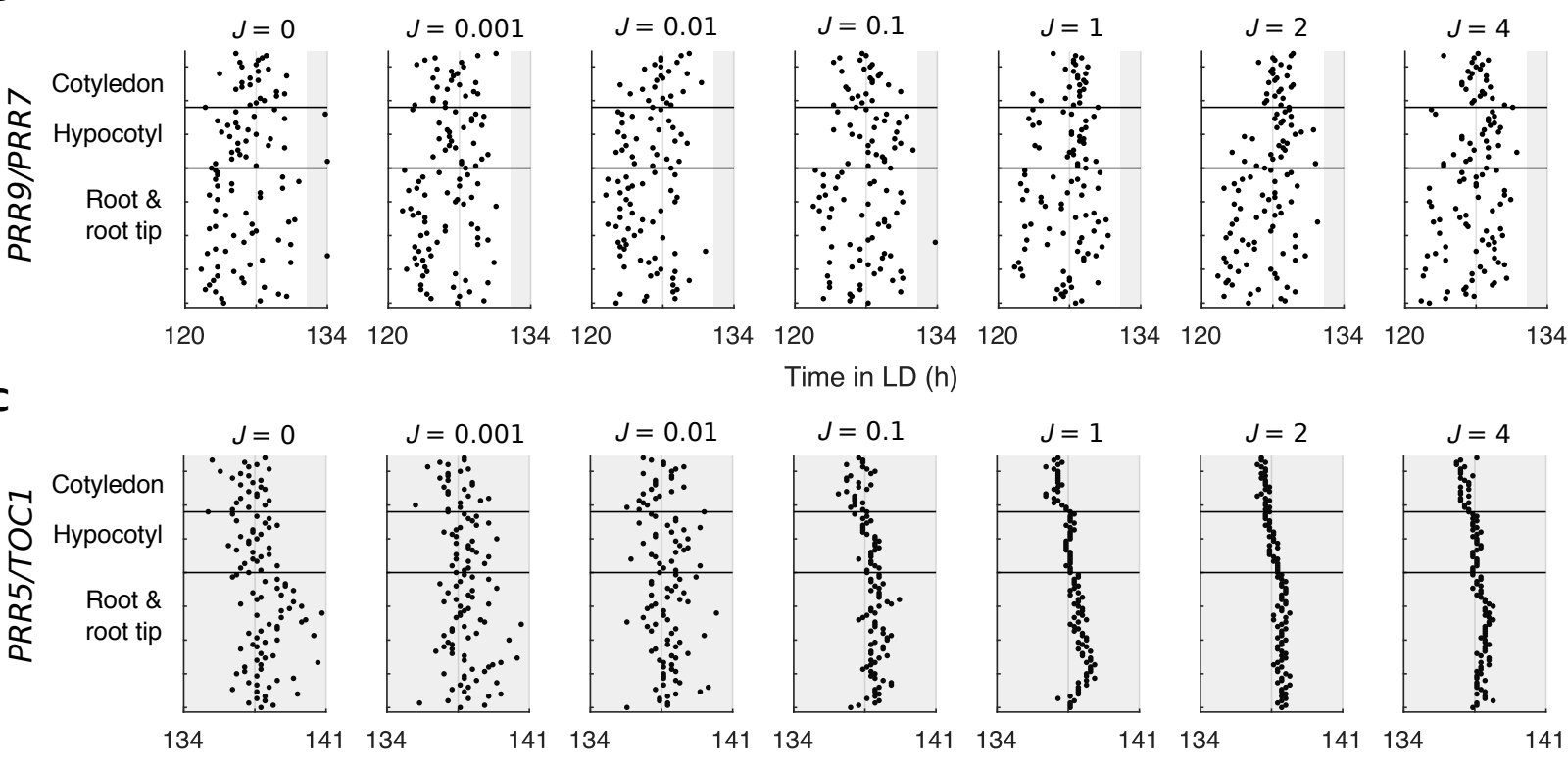

Time in LD (h)

D
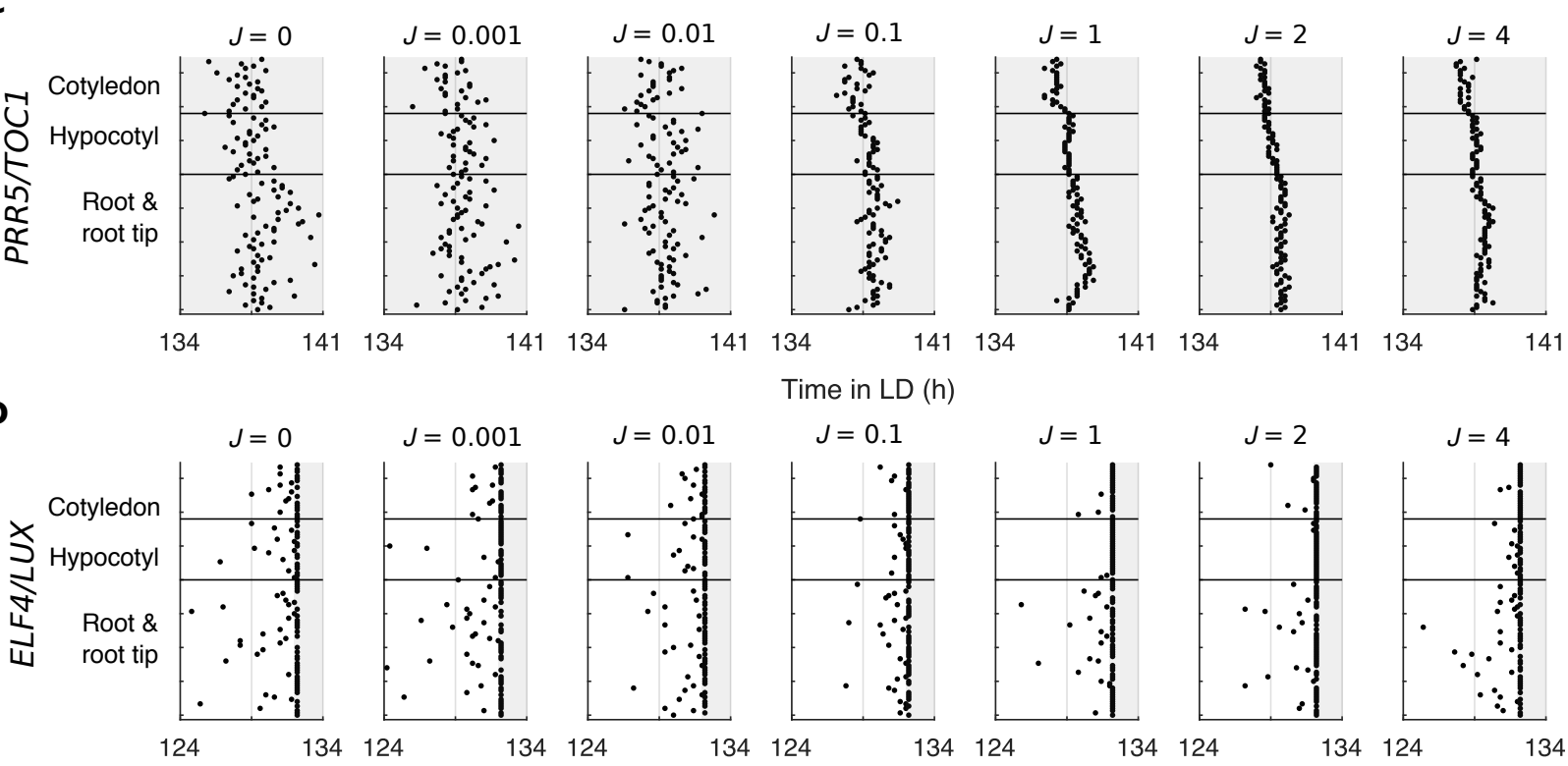

Time in LD (h)
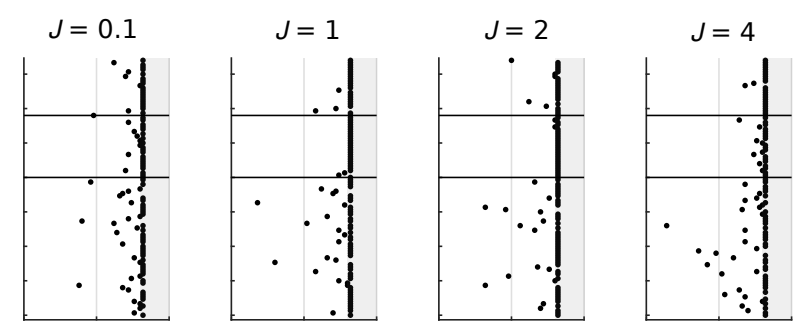

Time in LD (h)

S13 Fig. Times of the final simulated peaks of expression under noisy LD cycles with 
987 repression of ELF4 expression. CCA1, CIRCADIAN CLOCK ASSOCIATED 1; ELF4, EARLY

988 FLOWERING 4; LD, light-dark; LHY, LATE ELONGATED HYPOCOTYL; LUX, LUX

989 ARRHYTHMO; PRR, PSEUDO RESPONSE REGULATOR; TOC1, TIMING OF CAB

990 EXPRESSION 1.

991

992

993

994

995

996

997

998

999

1000

1001

1002

1003

1004

1005

1006

1007

1008

1009

1010 
A

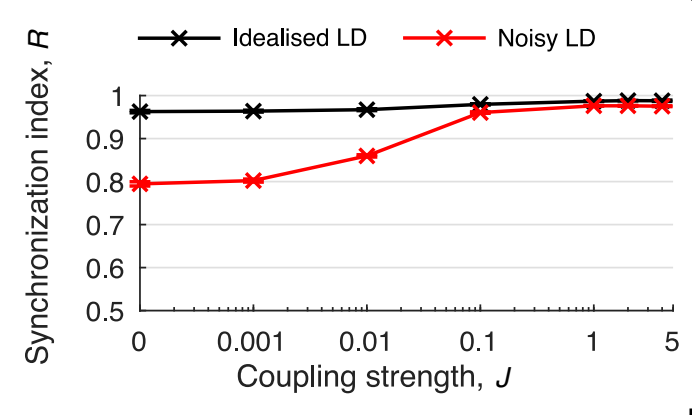

C

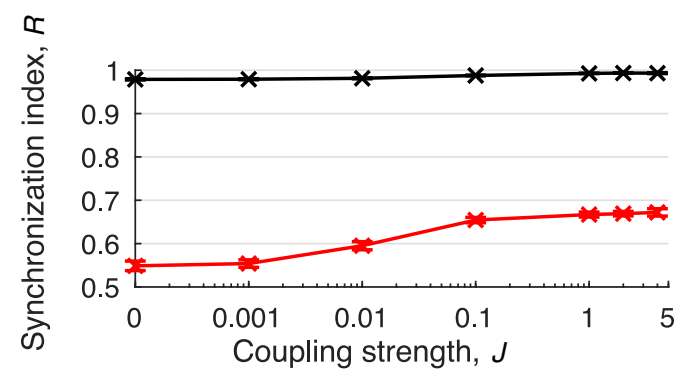

B

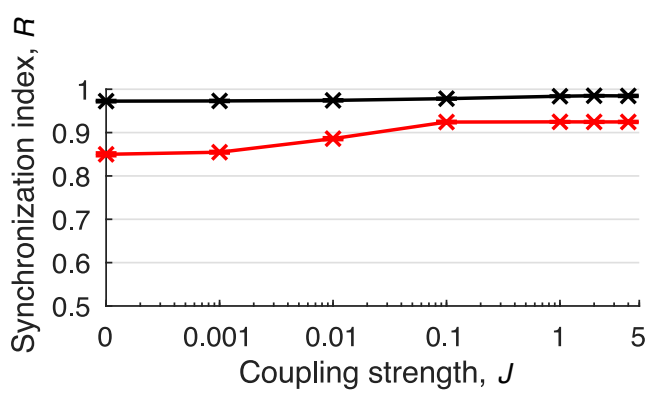

D

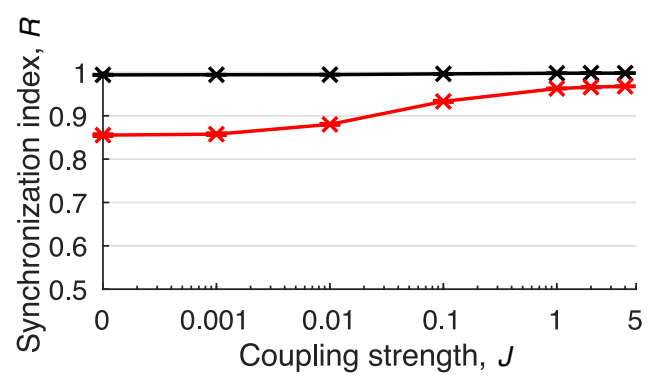

1012 S14 Fig. Cell-to-cell coupling increases the synchrony of protein oscillations under

1013 realistic LD cycles. (A-D) Quantification of phase coherence by the synchronization index, $R$,

1014 for simulated CCA1/LHY (A), PRR9/PRR7 (B), PRR5/TOC1 (C) or ELF4/LUX (D) protein

1015 expression under idealized or noisy LD cycles. Simulations included increasing strengths of

1016 coupling, J. Color legends are as in A. Data points represent the mean \pm standard deviation, $n=$

10179 simulations. CCA1, CIRCADIAN CLOCK ASSOCIATED 1; ELF4, EARLY FLOWERING 4; LD,

1018 light-dark; LHY, LATE ELONGATED HYPOCOTYL; LUX, LUX ARRHYTHMO; PRR, PSEUDO

1019 RESPONSE REGULATOR; TOC1, TIMING OF CAB EXPRESSION 1.

1020

1021

1022

1023

1024

1025

1026 
S1 Table. Parameter values for the spatial clock model.

\begin{tabular}{|c|c|c|c|}
\hline Parameter & Description & $\begin{array}{c}\text { Original value } \\
{[31]}\end{array}$ & $\begin{array}{c}\text { Re- } \\
\text { optimized } \\
\text { value }\end{array}$ \\
\hline$v_{1}$ & CCA1/LHY synthesis & $4.6 \mathrm{nM} \mathrm{h}^{-1}$ & $4.58 \mathrm{nM} \mathrm{h}^{-1}$ \\
\hline$v_{1 L}$ & CCA1/LHY light-induced synthesis & $3.0 \mathrm{nM} \mathrm{h}^{-1}$ & $3.0 \mathrm{nM} \mathrm{h}^{-1}$ \\
\hline$v_{2 A}$ & PRR9/PRR7 synthesis & $1.3 \mathrm{nM} \mathrm{h}^{-1}$ & $1.27 \mathrm{nM} \mathrm{h}^{-1}$ \\
\hline$v_{2 L}$ & $P R R 9 / P R R 7$ light-induced synthesis & $5.0 \mathrm{nM} \mathrm{h}^{-1}$ & $5.0 \mathrm{nM} \mathrm{h}^{-1}$ \\
\hline$v_{3}$ & PRR5/TOC1 synthesis & $1.0 \mathrm{nM} \mathrm{h}^{-1}$ & $1.0 \mathrm{nM} \mathrm{h}^{-1}$ \\
\hline$v_{4}$ & ELF4/LUX synthesis & $1.5 \mathrm{nM} \mathrm{h}^{-1}$ & $1.47 \mathrm{nM} \mathrm{h}^{-1}$ \\
\hline$k_{1 L}$ & CCA1/LHY mRNA degradation (light) & $0.53 \mathrm{~h}^{-1}$ & $0.53 \mathrm{~h}^{-1}$ \\
\hline$k_{1 D}$ & CCA1/LHY mRNA degradation (dark) & $0.21 \mathrm{~h}^{-1}$ & $0.21 \mathrm{~h}^{-1}$ \\
\hline$k_{2}$ & PRR9/PRR7 mRNA degradation & $0.35 \mathrm{~h}^{-1}$ & $0.35 \mathrm{~h}^{-1}$ \\
\hline $\boldsymbol{k}_{3}$ & PRR5/TOC1 mRNA degradation & $0.56 h^{-1}$ & $0.56 \mathrm{~h}^{-1}$ \\
\hline $\boldsymbol{k}_{4}$ & ELF4/LUX mRNA degradation & $0.57 \mathrm{~h}^{-1}$ & $0.57 \mathrm{~h}^{-1}$ \\
\hline$p_{1}$ & CCA1/LHY translation & $0.76 \mathrm{~h}^{-1}$ & $0.76 \mathrm{~h}^{-1}$ \\
\hline$p_{1 L}$ & CCA1/LHY light-induced translation & $0.42 \mathrm{~h}^{-1}$ & $0.42 h^{-1}$ \\
\hline$p_{2}$ & PRR9/PRR7 translation & $1.0 \mathrm{~h}^{-1}$ & $1.01 \mathrm{~h}^{-1}$ \\
\hline$p_{3}$ & PRR5/TOC1 translation & $0.64 \mathrm{~h}^{-1}$ & $0.64 \mathrm{~h}^{-1}$ \\
\hline$p_{4}$ & ELF4/LUX translation & $1.0 \mathrm{~h}^{-1}$ & $1.01 \mathrm{~h}^{-1}$ \\
\hline$d_{1}$ & CCA1/LHY degradation & $0.68 \mathrm{~h}^{-1}$ & $0.68 \mathrm{~h}^{-1}$ \\
\hline$d_{2 D}$ & PRR9/PRR7 degradation (dark) & $0.51 \mathrm{~h}^{-1}$ & $0.5 \mathrm{~h}^{-1}$ \\
\hline$d_{2 L}$ & PRR9/PRR7 degradation (light) & $0.30 \mathrm{~h}^{-1}$ & $0.29 \mathrm{~h}^{-1}$ \\
\hline$d_{3 D}$ & PRR5/TOC1 degradation (dark) & $0.48 \mathrm{~h}^{-1}$ & $0.48 \mathrm{~h}^{-1}$ \\
\hline$d_{3 L}$ & PRR5/TOC1 degradation (light) & $0.78 \mathrm{~h}^{-1}$ & $0.78 \mathrm{~h}^{-1}$ \\
\hline$d_{4 D}$ & ELF4/LUX degradation (dark) & $1.2 \mathrm{~h}^{-1}$ & $1.21 \mathrm{~h}^{-1}$ \\
\hline$d_{4 L}$ & ELF4/LUX degradation (light) & $0.38 \mathrm{~h}^{-1}$ & $0.38 \mathrm{~h}^{-1}$ \\
\hline$K_{0}$ & Inhibition of CCA1/LHY by CCA1/LHY & $\mathrm{n} / \mathrm{a}$ & $5.07 \mathrm{nM}$ \\
\hline$K_{1}$ & Inhibition of CCA1/LHY by PRR9/PRR7 & $0.16 \mathrm{nM}$ & $0.16 \mathrm{nM}$ \\
\hline$K_{2}$ & Inhibition of CCA1/LHY by PRR5/TOC1 & $1.2 \mathrm{nM}$ & $1.18 \mathrm{nM}$ \\
\hline$K_{4}$ & Inhibition of PRR9/PRR7 by PRR5/TOC1 & $0.23 \mathrm{nM}$ & $0.40 \mathrm{nM}$ \\
\hline$K_{5}$ & Inhibition of PRR9/PRR7 by ELF4/LUX & 0.30 & $0.62 \mathrm{nM}$ \\
\hline$K_{5 b}$ & Inhibition of PRR9/PRR7 by CCA1/LHY & $\mathrm{n} / \mathrm{a}$ & $1.2 \mathrm{nM}$ \\
\hline$K_{6}$ & Inhibition of PRR5/TOC1 by CCA1/LHY & 0.46 & $0.46 \mathrm{nM}$ \\
\hline$K_{7}$ & Inhibition of PRR5/TOC1 by PRR5/TOC1 & 2.0 & $2.0 \mathrm{nM}$ \\
\hline$K_{8}$ & Inhibition of ELF4/LUX by CCA1/LHY & 0.36 & $0.36 \mathrm{nM}$ \\
\hline$K_{9}$ & Inhibition of ELF4/LUX by PRR5/TOC1 & 1.9 & $1.9 \mathrm{nM}$ \\
\hline$K_{10}$ & Inhibition of ELF4/LUX by ELF4/LUX & 1.9 & $1.9 \mathrm{nM}$ \\
\hline
\end{tabular}


1031 S1 Video. Time-lapse of simulated PRR9/PRR7 expression under LL. Representative

1032 simulation of simulated PRR9/PRR7 expression from individual cells of the plant template 24-

$1033144 \mathrm{~h}$ after transfer to LL. LL, constant light; PRR, PSEUDO RESPONSE REGULATOR.

1034

1035 S2 Video. Time-lapse of PRR9::LUC expression under LL. PRR9::LUC expression from a

1036 single representative seedling 24-144 h after transfer to LL. LL, constant light; PRR9, PSEUDO

1037 RESPONSE REGULATOR9. 